\title{
A revision of the flutter margin method to predict in real-time the limit cycle oscillations onset speed with structural freeplay present in the plunge axis
}

\author{
JL Casado Corpas', A Sanz-Lobera', I González-Requena' \\ and L Sevilla ${ }^{1,2}$
}

\begin{abstract}
Computational fluid dynamic and order reducing methods have been extensively applied to predict the flutter onset speed of several types of aircrafts. However, the accuracy required by certification standards still ascribes flight testing as the only method available that safely validates the flight envelope of an aircraft. In particular, free-flutter conditions must be demonstrated in the target flight envelope, and several methods have been developed to determine the flutter onset speed in real-time when expanding the envelope during flight testing. Among the methods, the damping versus velocity technique combined with a flutter margin implementation remains the most common technique used for envelope expansion. Even with the popularity and "easy to implement" characteristics of this method, several shortcomings can adversely affect the identification of non-stable conditions during envelope expansion. Notably, the limit cycle oscillations conditions, distinct from flutter, cannot be accurately identified. This study proposes to apply a similar methodology to the flutter margin to anticipate limit cycle oscillations associated with freeplay in the plunge axis of a bi-dimensional airfoil that is aeroelastically representative of the tested aircraft. Analytical considerations are conducted to support this new approach, and a computer model is used to validate the proposed methodology.
\end{abstract}

\section{Keywords}

Flutter margin, limit cycle oscillations, aeroelasticity

\section{Introduction}

Currently, the flutter margin (FM) concept ${ }^{1}$ appears as a valuable tool to predict the flutter boundaries during flight testing. However, the main hypothesis of that concept, which is based on two linear structural modes (typically torsion and bending, whose characteristic frequencies merge as the airspeed increases), produces low reliability when nonlinearities are present. When performing flight flutter tests, limit cycle oscillation (LCO) conditions cannot be easily distinguished in real-time from flutter, identifying an excessively conservative flutter envelope. LCOs can arise when structural and/or aerodynamic non-linearities produce aeroelastic instability. Theoretical and practical investigations have been performed regarding structural nonlinearities such as freeplay, ${ }^{2} 5$ large amplitudes, ${ }^{6,7}$ and non-linear stiffness. ${ }^{8,9}$ Several studies have been performed to determine the influence of unsteady ${ }^{10,11}$ and transonic ${ }^{12,13}$ aerodynamics on LCO generation. However, a definite on-line methodology to reliably predict a phenomenon such as LCOs from flight data by evaluating the distinctive characteristics of LCOs with respect to classic flutter remains as one of the most important techniques to develop. ${ }^{14} 17$

In the present paper, a revision of the FM concept is proposed to predict LCOs when expanding the flight envelope; the prediction employs real-time flight data when freeplay non-linearities in the plunge axis are present. To implement this conceptual approach, the content and organization of this paper have been arranged in two main parts. The first part proposes an LCO mechanism based on a bidimensional airfoil model that displays freeplay in

\footnotetext{
'Departamento de Materiales y Producción Aeroespacial, Universidad Politécnica de Madrid, Spain

${ }^{2}$ Departamento de Ingenieria Civil Materiales y Fabricación.

Universidad de Málaga, Spain

Corresponding author:

A Sanz-Lobera, Departamento de Materiales y Producción

Aeroespacial, Universidad Politécnica de Madrid, Spain.

Email: a.slobera@upm.es
} 
the plunge axis and quasi-steady aerodynamics. The second part validates this concept against a Simulink Model and a real F18 test case. The Simulink Model implements, in a virtual scenario, the classical methodology that can be found when performing real flight flutter tests. For the F18 real test, previously published data $^{5}$ are used. Finally, conclusions and recommendations are provided for future refinements of the proposed concept.

\section{Problem formulation}

The aeroelastic system is modeled as a two degrees-offreedom ( 2 d.o.f.) airfoil with freeplay permitted in the plunging motion. To develop a fully analytical method and to maintain the physical significance, structural damping is not implemented and quasisteady aerodynamic forces are incorporated. The proposed model is considered representative when flutter or LCOs develop because under these specific conditions, only two main aeroelastic modes are prevalent, typically in the bending and torsion axes.

\section{Equations of motion}

The model, along with the sign criteria, is schematically shown in Figure 1. The popular bending/ torsion idealization (with freeplay in the plunge axis) is used to develop the equations. Elastic linear restraints, bending and torsion are applied about the elastic axis. Aerodynamic forces, consisting of lift and the pitching moment, also refer to the elastic axis.

- Aerodynamic forces: Lift (L) and Moment (M)

$$
\begin{aligned}
& L=-2 \pi \rho b(\dot{h}+U \alpha) U \\
& M=2 \pi \rho b^{2}(\dot{h}+U \alpha)\left(a+\frac{1}{2}\right) U
\end{aligned}
$$

Equations of motion can be expressed as the following

$$
\begin{aligned}
& m \ddot{h}+2 \pi \rho b U \dot{h}+S_{\alpha} \ddot{\alpha}+2 \pi \rho b U^{2} \alpha=F_{h} \\
& S_{\alpha} \ddot{h}-2 \pi \rho b^{2}\left(a+\frac{1}{2}\right) U \dot{h}+I_{\alpha} \ddot{\alpha} \\
& \quad-2 \pi \rho b^{2}\left(a+\frac{1}{2}\right) U^{2} \alpha=F_{\alpha}
\end{aligned}
$$

where $S_{\alpha}=m b x_{\alpha}$ is the static mass moment per unit span about the elastic axis, and $F_{\alpha}$ and $F_{h}$ are the structural forces, respectively, in the plunge and pitch axis. According to the main hypothesis, $F_{\alpha}$ is linear and $F_{h}$ is only linear outside the $[-\delta / 2+\delta / 2]$ range (Figure 2).
Because the freeplay in plunge is limited to $[-\delta / 2+\delta / 2]$ range, the analysis of the governing equations can be performed independently in three different areas:

For each Area defined in Table 1, first motion equation (3) changes, whereas the second motion equation (4) related to the pitch axis remains unchanged. Therefore, the first motion equation (3) can be expressed, for each area, as follows

\section{- Area I}

$$
m \ddot{h}+2 \pi \rho b U \dot{h}+K_{h} h+S_{u} \ddot{\alpha}+2 \pi \rho b U^{2} \alpha-K_{h} \frac{\delta}{2}=0
$$

- Area II

$$
m \ddot{h}+2 \pi \rho b U \hat{h}+S_{\alpha} \ddot{\alpha}+2 \pi \rho b U^{2} \alpha=0
$$

\section{- Area III}

$$
m \ddot{h}+2 \pi \rho b U \dot{h}+K_{h} h+S_{u} \ddot{\alpha}+2 \pi \rho b U^{2} \alpha+K_{h} \frac{\delta}{2}=0
$$

To develop a conceptual assessment, the dynamic behavior defined by the above equations (4) to (7) can be evaluated by setting $\delta=0$. In that case, only the following equations can be considered

$$
\begin{gathered}
m \ddot{h}+2 \pi \rho b U \dot{h}+K_{h} h+S_{u} \ddot{\alpha}+2 \pi \rho b U^{2} \alpha=0 \\
S_{u} \ddot{h}-2 \pi \rho b^{2}\left(a+\frac{1}{2}\right) U \dot{h}+I_{u} \ddot{\alpha} \\
+\left(K_{u}-2 \pi \rho b^{2}\left(a+\frac{1}{2}\right) U^{2}\right) \alpha=0
\end{gathered}
$$

The variables are altered as shown as follows

$$
\begin{aligned}
& h_{1}=h: h_{2}=\dot{h} ; \dot{h}_{1}=h_{2}: \dot{h_{2}}=\ddot{h} ; \alpha_{1}=\alpha \\
& \alpha_{2}=\dot{\alpha} ; \quad \dot{\alpha}_{1}=\alpha_{2} ; \dot{\alpha}_{2}=\ddot{\alpha}
\end{aligned}
$$

The following expressions are obtained

$$
\begin{aligned}
& \dot{h}_{1}=h_{2} \\
& \dot{h}_{2}=-\mu U h_{2}-\omega_{h}^{2} h_{1}-\mu U^{2} \alpha_{1}-b x_{\alpha} \dot{\alpha}_{2} \\
& \dot{\alpha}_{1}=\alpha_{2}
\end{aligned}
$$

$$
\dot{\alpha}_{2}=\frac{1}{b\left(x_{\alpha}^{2}-r_{\alpha}^{2}\right)}\left\{\begin{array}{l}
{\left[b r_{\alpha}^{2} \omega_{\alpha}^{2}-U^{2} \mu\left(x_{\alpha}+a+\frac{1}{2}\right)\right] \alpha_{1}} \\
-U \mu\left(x_{\alpha}+a+\frac{1}{2}\right) h_{2}-x_{\alpha} \omega_{h}^{2} h_{1}
\end{array}\right\}
$$




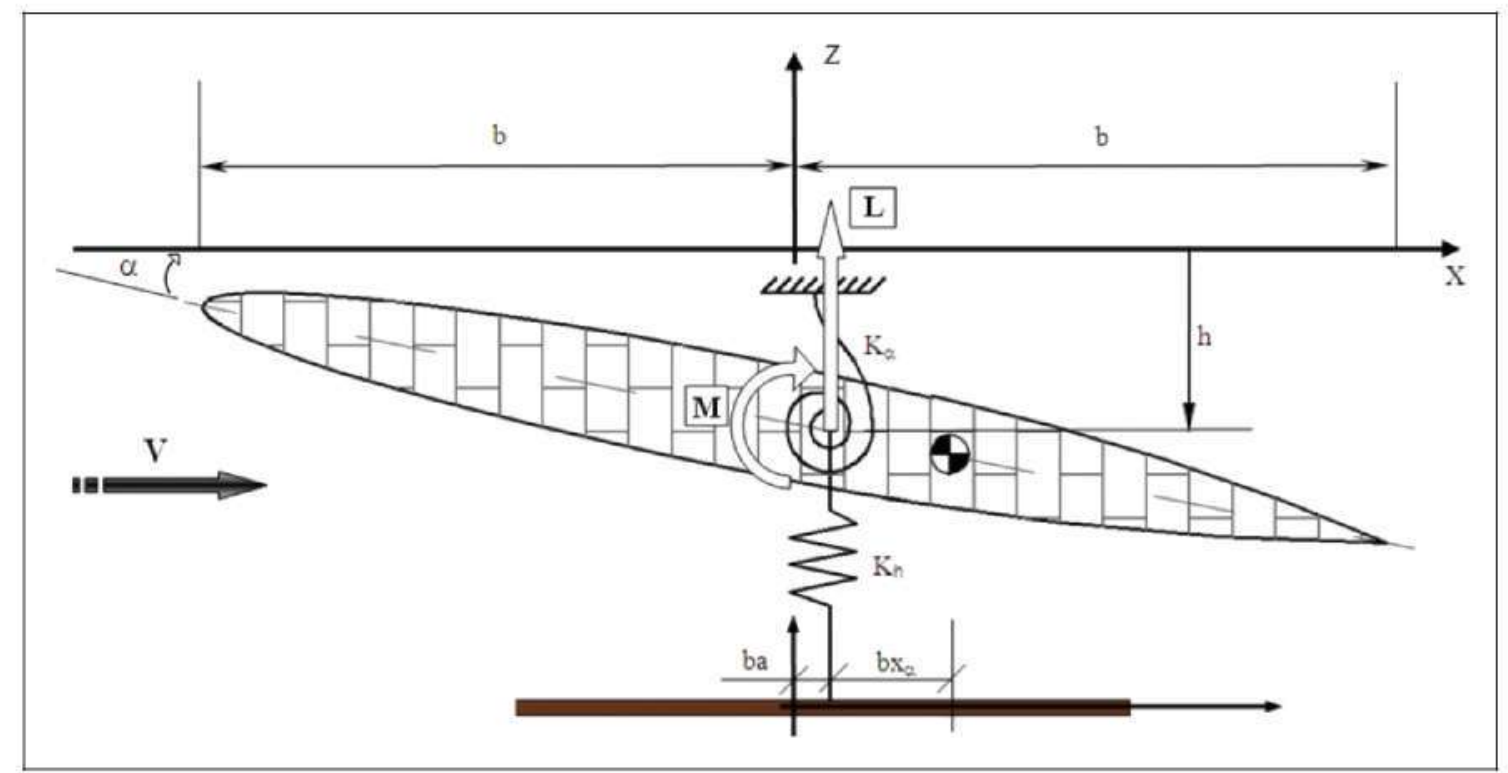

Figure I. Airfoil model with plunge and pitch motion restrained by springs.

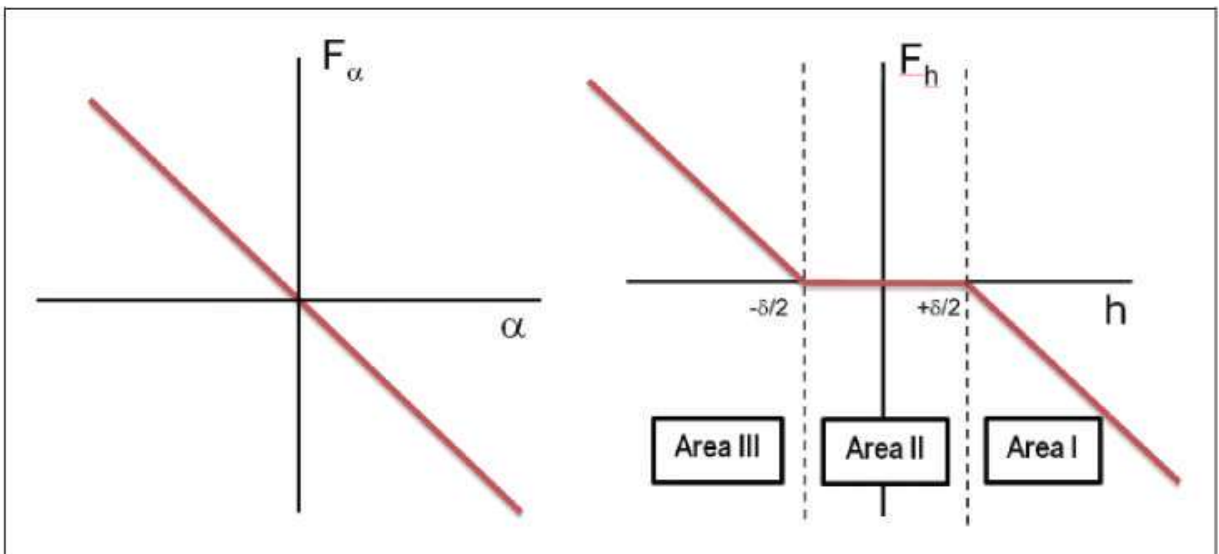

Figure 2. Bending and torsion idealization: pitch and plunge spring models.

where the bending and torsion structural natural fre- where quencies are the following

$$
\begin{aligned}
& \omega_{h}^{2}=\frac{K_{h}}{m} \\
& \omega_{\alpha}^{2}=\frac{K_{\alpha}}{I_{\alpha}}
\end{aligned}
$$

and the mass parameter is as follows

$$
\mu=\frac{2 \pi \rho b}{m}
$$

Equations (11) through equation (14) are rearranged in matrix notation

$$
\left[\begin{array}{c}
\dot{h}_{1} \\
\dot{h}_{2} \\
\dot{\alpha}_{1} \\
\dot{\alpha}_{2}
\end{array}\right]=\left[\begin{array}{cccc}
0 & 1 & 0 & 0 \\
a_{21} & a_{22} & a_{23} & 0 \\
0 & 0 & 0 & 1 \\
a_{41} & a_{42} & a_{43} & 0
\end{array}\right]\left[\begin{array}{l}
h_{1} \\
h_{2} \\
\alpha_{1} \\
\alpha_{2}
\end{array}\right]
$$

$$
\begin{gathered}
a_{23}=\frac{1}{x_{\alpha}^{2}-r_{\alpha}^{2}}\left(U^{2} \mu\left(r_{\alpha}^{2}+x_{\alpha}\left(a+\frac{1}{2}\right)\right)-b r_{\alpha}^{2} \omega_{\alpha}^{2}\right) \\
a_{41}=\frac{x_{\alpha} \omega_{h}^{2}}{b\left(x_{\alpha}^{2}-r_{\alpha}^{2}\right)} \\
a_{42}=-\frac{\mu\left(x_{\alpha}+a+\frac{1}{2}\right)}{b\left(x_{\alpha}^{2}-r_{\alpha}^{2}\right)} U \\
a_{43}=\frac{1}{b\left(x_{\alpha}^{2}-r_{\alpha}^{2}\right)}\left(b r_{\alpha}^{2} \omega_{\alpha}^{2}-\mu\left(x_{\alpha}+a+\frac{1}{2}\right) U^{2}\right)
\end{gathered}
$$


Table I. Elastic forces (plunge axis) considered within each area.

\begin{tabular}{lll}
\hline & Geometrical condition & Elastic force \\
\hline Area I: & $h \geqslant+/ 2$ & $F_{h}=-K_{h}(h-/ 2)$ \\
Area II: & $-/ 2<h</ 2$ & $F_{h}=0$ \\
Area III: & $h \leqslant-/ 2$ & $F_{h}=-K_{h}(h+/ 2)$ \\
\hline
\end{tabular}

The overall behavior of the airfoil is provided by the characteristic equation of the $[4 \times 4]$ matrix defined by the terms $a_{21}, a_{22}, a_{23}, a_{41}, a_{42}$, and $a_{43}$. This equation will be different depending on every instant plunge value. When the airfoil is within the freeplay range (Area II), no bending stiffness is considered. When the airfoil is outside the freeplay range (Areas I and III), the bending stiffness must be considered.

In Area II, freeplay is present in the plunge. Therefore, $K_{h}=\omega_{h}=0$ and coefficients $a_{21}=a_{41}=0$. Equation (18) transforms into the following

$$
\left[\begin{array}{c}
\dot{h}_{1} \\
\dot{h}_{2} \\
\dot{\alpha}_{1} \\
\dot{\alpha}_{2}
\end{array}\right]=\left[\begin{array}{cccc}
0 & 1 & 0 & 0 \\
0 & a_{22} & a_{23} & 0 \\
0 & 0 & 0 & 1 \\
0 & a_{42} & a_{43} & 0
\end{array}\right]\left[\begin{array}{l}
h_{1} \\
h_{2} \\
\alpha_{1} \\
\alpha_{2}
\end{array}\right]
$$

Low values of the mass parameter (17) results in the characteristic equation (expressed algebraically as an eigenvalue equation)

$$
p^{2}-a_{22 p}-a_{43}=0
$$

Within Areas I and III, a linear stiffness in the plunge is present and, hence, $K_{h} \neq 0$. Therefore, coefficients $a_{21} \neq a_{41} \neq 0$. In this case, the characteristic equation obtained from equation (18) when $a_{2 l} \cdot a_{43}$ is considered small, produces the following

$$
p^{2}-a_{22} p-\left(a_{43}+a_{21}\right)=0
$$

In summary, within the freeplay range [Area II], the following can be written as

$$
p_{\text {FREEPLAY }}=\frac{a_{22} \pm \sqrt{a_{22}^{2}+4 a_{43}}}{2}
$$

Outside the freeplay range [Areas I and III], the following can be written as

$p_{\text {NONFREEPLAY }}=\frac{a_{22} \pm \sqrt{a_{22}^{2}+4\left(a_{43}+a_{21}\right)}}{2}, a_{21}<0$

Consequently, the different dynamic behaviors of the airfoil within or outside the freeplay range depend on the magnitude of $a_{21}$; the term $a_{21}$ is the only difference between the two above equations. Additionally, because $a_{21}$ is always negative, the stability of the system depends on the inertia in the pitch axis and the structural plunge stiffness of the airfoil with respect to the terms $a_{22}$ and $a_{43}$, which mainly depend on the speed. Therefore, to achieve LCOs at speeds below flutter onset speeds when freeplay is noted in the plunge, a slightly divergent behavior must be permitted in the freeplay area. This behavior defines a clear LCO mechanism. When divergent behavior within the no-freeplay area is permitted, these system characteristics produce flutter without LCOs. Translating these conclusions into a phase plane defined by the plunge and plunge rate, the necessary condition to achieve LCOs at speeds below flutter onset is to have a system stationary state defined by a slightly divergent behavior within the freeplay range and a convergent behavior outside the freeplay range. In summary, two possible paths could be defined in the phase plane (Figure 3 ).

The green closed curve corresponds to a stable LCO composed of a slightly divergent phase in the freeplay area plus a convergent phase in the no-freeplay area (completely defined by boundary conditions in points 1 to 4 ). This configuration is fully compatible with the solutions proposed in the above paragraphs. Orange closed curve corresponds to a degraded behavior of LCO and it is not considered in the present paper.

To determine the LCO mechanism, the following conditions must be present:

1. Within Areas I and III, the airfoil dynamics must be stable. From a mathematical point of view, the expected kinematics should be modelled by $e^{-\mathrm{t}} \sin (\mathrm{t})$

2. Within Area II, the airfoil dynamics must be slightly divergent. From a mathematical point of view, the expected kinematics should be modelled by $e^{+\mathrm{dt}}$.

These conditions allow writing the general equation for the airfoil kinematics within Areas I and III

$$
h_{\mathrm{I}, \mathrm{III}}=A e^{-5 t} \sin (t+\varphi)
$$

According to equation (30), the time required by the airfoil to pass through Area I or Area III is the half characteristic time

$$
\Delta t_{\mathrm{I}, \mathrm{III}}=\pi / \omega
$$

The general equation for the airfoil kinematics within Area II is as follows

$$
\begin{aligned}
& h_{\mathrm{II}}=B+C e^{+b t} \\
& \dot{h}_{\mathrm{II}}=C \cdot b \cdot e^{+b t}
\end{aligned}
$$




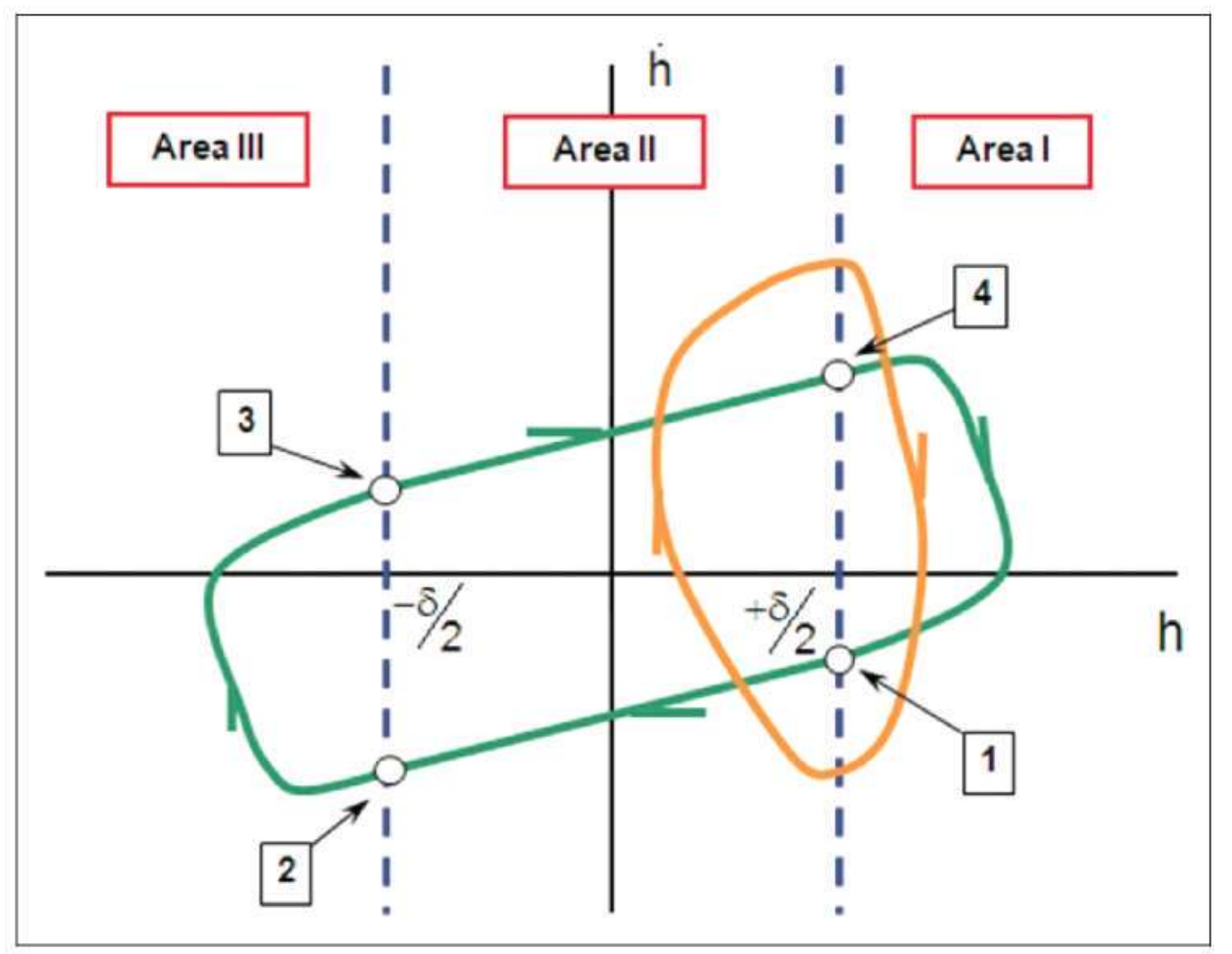

Figure 3. LCO considered paths in the phase plane.

Considering that the freeplay is small within Area II, equation (33) can be linearized

$$
\dot{h}_{\mathrm{II}}=C \cdot b+c \cdot b^{2} \cdot t
$$

Therefore, within the freeplay Area II, the time required by the airfoil to pass through this Area is the following

$$
\begin{aligned}
& \Delta h_{\Pi \mathrm{I}}=\delta=C \cdot b \cdot \Delta t_{\mathrm{II}} \\
& \Delta t_{\mathrm{II}}=\delta / C \cdot b
\end{aligned}
$$

In addition, the acceleration remains constant and equals the following

$$
\ddot{h}_{\mathrm{II}}=C \cdot b^{2}
$$

Because LCOs are periodic and a chaotic state is not considered in this paper, the curve described by the plunge and plunge rate within the state space must be closed. ${ }^{16,18}$ The following conditions apply to points 1 to 4 within the Phase Plane (Figure 3 ) during one cycle.

Starting at point 1 and following the cycle from right to left, the pair [h, h'] in each point is the following

$$
\text { Point 1: } \quad h_{1}=+\frac{\delta}{2}, \dot{h_{1}}=\dot{h_{1}}
$$

Point 2: $\quad h_{2}=-\frac{\delta}{2}, \dot{h}_{2}=\dot{h}_{1}-\left(\ddot{h}_{\mathrm{II}} \cdot \Delta t_{\mathrm{II}}\right)$

$$
=\dot{h}_{1}-C \cdot b^{2} \cdot \delta / C \cdot b=\dot{h}_{1}-b \delta
$$

$$
\begin{aligned}
& \text { Point 3: } \quad h_{3}=-\frac{\delta}{2}, \dot{h_{3}}=-\dot{h_{2}} \cdot e^{-\frac{\xi \pi}{\omega}} \\
& \begin{aligned}
\text { Point 4: } \quad h_{4}=+\frac{\delta}{2}, \dot{h}_{4}=\dot{h}_{3}-\left(\ddot{\mathrm{h}_{\mathrm{II}}} \cdot \Delta t_{\mathrm{II}}\right) \\
=\dot{h}_{3}+C \cdot b^{2} \cdot \delta / C \cdot b=\dot{h}_{3}+b \delta
\end{aligned}
\end{aligned}
$$

Point 1: $\quad h_{1}=+\frac{\delta}{2}, \dot{h_{1}}=-\dot{h}_{4} \cdot e^{-\frac{b \pi}{\omega}}$

Equation (42) sets the necessary condition for the airfoil to show a cyclic behavior (and display a closed curve in the phase plane).

From equations (42) and (41), the following expression is obtained

$$
\dot{h}_{1}=-\left(\dot{h_{3}}+b \delta\right) \cdot e^{-\frac{k \pi}{\omega}}
$$

From equations (43) and (40), the following expression is obtained

$$
\dot{h_{1}}=-\left(\dot{h_{2}} \cdot e^{\frac{-5 \pi}{\omega}}+b \delta\right) \cdot e^{\frac{-5 \pi}{\omega}}
$$

From equations (43) and (38), the equation governing the necessary condition for an LCO is as follows

$$
\dot{h}_{1}=\left(\left(\dot{h_{1}}-b \delta\right) \cdot e^{-\frac{b \pi}{\omega}}-b \delta\right) \cdot e^{\frac{b \pi}{\omega}}
$$




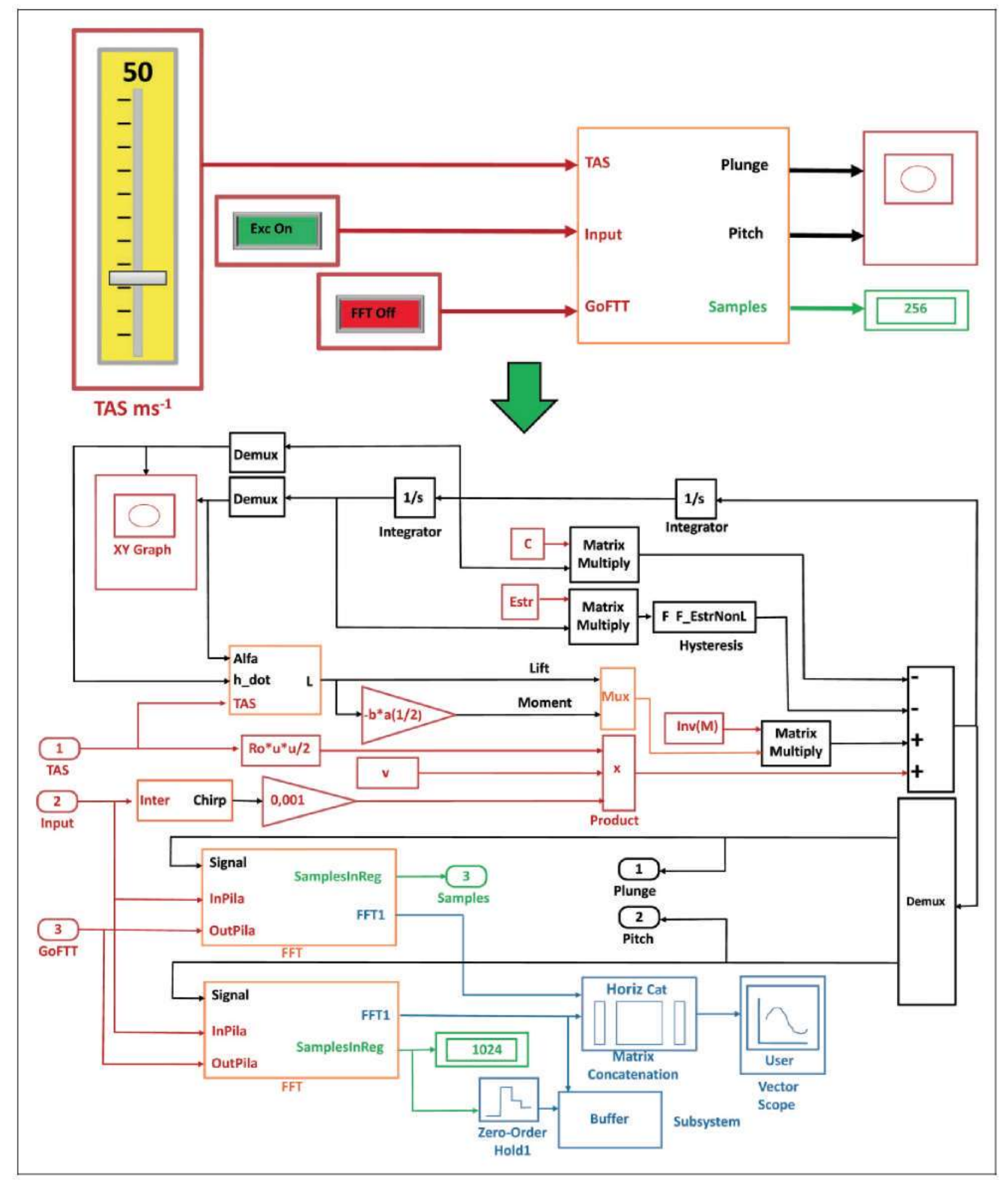

Figure 4. Interactive bi-dimensional Matlab-Simulink Model.

Re-arranging the equation produces the following

$\frac{b \delta}{\dot{h_{1}}}=\frac{e^{-\frac{2 b \pi}{\omega}}-1}{e^{-\frac{b \pi}{\omega}}+e^{-\frac{2 \gamma \pi}{\omega}}}$

Because the freeplay is not usually known in advance, a mathematical condition independent of $\frac{b \delta}{h_{1}}$ must be found. After the LCO is noted for the first time, it persists until the flutter is encountered. Therefore, $\frac{b \delta}{h_{1}}=0$ is a necessary condition for the LCO to be activated. Additionally, that condition should persist in time. So, a LCO Margin function could be defined as

$$
F_{\mathrm{LCO}} \equiv e^{-\frac{2 \mathrm{zG \pi}}{a}}-1
$$




\section{Practical application to a simulation model}

To apply the methodology linked to the LCO Margin defined in the above paragraph, an interactive Matlab-Simulink model has been developed to simulate the "real world" flight test envelope expansion procedure. The model is outlined in Figure 4.

When performing the envelope expansion, the following procedure is usually applied: ${ }^{15,19,20}$

- The aircraft is excited, and the vibration response is measured using accelerometers and/or strain gages.

- The data are curve-fitted using system identification methods to determine the model parameters and track the modes of interest.

- Using decision tools, i.e., FM estimator or even the experience of the test, the test progresses through the flight conditions.

The simulation model is composed of two different parts:

1. A bi-dimensional (plunge and pitch) aeroelastic model in which the user can set the airspeed in real-time. This implementation assumes incompressible flow and "quasi-steady" aerodynamics.

2. An excitation system (chirp signal in pitch ranging from 0 to $20 \mathrm{~Hz}$ ) and a "real-time" Fourier analysis of the obtained signals in both plunge and pitch channels.

Once the above model was validated using previously published data, ${ }^{1618,20}$ the model was used to simulate the envelope expansion procedure and apply both the Flutter and LCO margins with and without freeplay in the plunge axis. The results are shown for the following model parameters (representative of real fighter aircrafts): $\mu=0.2462 ; r_{\alpha}=0.6325 ; x_{\alpha}=0.375$; $\omega_{h}=5 \mathrm{~Hz} ; \omega_{\alpha}=9 \mathrm{~Hz}$. To provide clear conclusions, a pitch control surface deflection "chirp shaped" ranging from 0 to $20 \mathrm{~Hz}$ was selected as the excitation input (Figure 5).

\section{Simulation results}

Two sets of data, with and without freeplay, are provided. In both cases, the data are presented with the identical axis definition to facilitate the analysis. Each set of data provides the plunge and pitch time history response to the defined "chirp shaped" input and its Fourier Transform. This scheme is shown at different airspeeds: $20,30,40,50$, and $60 \mathrm{~m} / \mathrm{s}$ for nofreeplay cases and 20,40 , and $54 \mathrm{~m} / \mathrm{s}$ for freeplay cases $(\delta=[-0.01+0.01])$. Additionally, the FM technique and the proposed LCO margin (following a realistic envelope expansion procedure) are also presented.

\section{No freeplay: Modes evolution with free stream speed}

\section{Free stream speed: $20 \mathrm{~m} / \mathrm{s}$}

Once stabilized at $20 \mathrm{~m} / \mathrm{s}$, the excitation in the pitch axis is launched according to the pattern shown in Figure 5. The airfoil time response in both the plunge and pitch axis is buffered (Figure 6). After the airfoil response finishes, the FFT is launched (Figure 7). The airfoil response is almost negligible, and faster speeds are required to maintain the "envelope expansion" process.

\section{Free stream speed: $40 \mathrm{~m} / \mathrm{s}$}

At $40 \mathrm{~m} / \mathrm{s}$, the airfoil response is noted (Figure 8). Two characteristic modes are clearly distinguished in both the time and frequency planes: $5.2 \mathrm{~Hz}$ in the plunge and $9.6 \mathrm{~Hz}$ in the pitch (Figure 9). This behavior is representative of fighter aircrafts. Fighter aircrafts usually display a greater stiffness in pitch (torsion) than in plunge. In addition, the high damping in both modes allows the process to continue and decreases the time required to enter the next stage.

\section{Free stream speed: $50 \mathrm{~m} / \mathrm{s}$}

At $50 \mathrm{~m} / \mathrm{s}$, the damping of the response is clearly degraded (Figure 10). However, once the excitation finishes, the airfoil returns to a steady position. At this speed, the frequencies of the characteristic modes move in a "coalescence" behavior. The plunge characteristic frequency increases up to $5.6 \mathrm{~Hz}$, whereas the pitch decreases to $9.1 \mathrm{~Hz}$ (Figure 11). In addition, the FM degrades from 21,200 to 13,200 , anticipating flutter.

\section{Free stream speed: $60 \mathrm{~m} / \mathrm{s}$}

At $60 \mathrm{~m} / \mathrm{s}$, the coalescence mechanism and the small damping modes are confirmed (Figure 12). The plunge characteristic frequency increases to $6.4 \mathrm{~Hz}$ and the pitch decreases to $7.7 \mathrm{~Hz}$ (Figure 13). In this case, the FM is degraded from 13,200 to 1700 (Figure 14). In a realistic scenario at this stage, the envelope expansion process must stop because the flutter onset speed is close. By matching the FM values to a cubic function, a flutter onset speed of $62 \mathrm{~m} / \mathrm{s}$ is anticipated. The airfoil response became unstable at $64 \mathrm{~m} / \mathrm{s}$. As expected, the $F M$ provided conservative flutter speed estimations.

\section{Freeplay $\delta=[-0.01+0.01] \mathrm{m}$ : Modes evolution with free stream speed}

\section{Free stream speed: $20 \mathrm{~m} / \mathrm{s}$}

Following a similar process as shown in the previous paragraph, the freeplay in the plunge is noticeable 


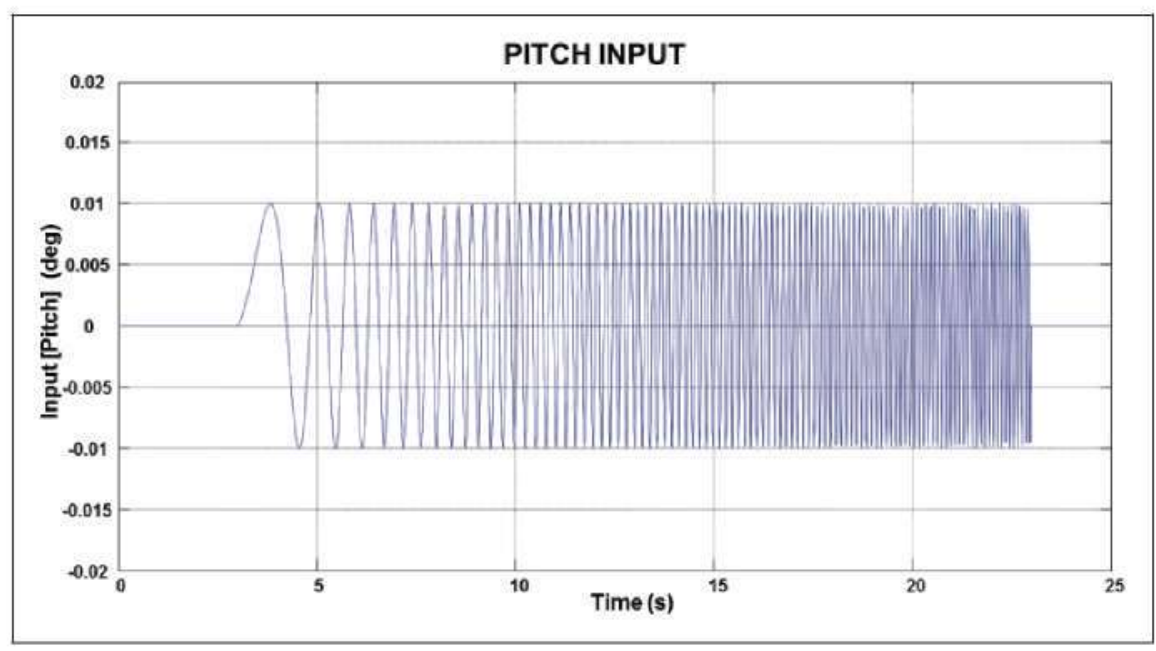

Figure 5. Input signal: Pitch control surface deflection "chirp shaped."

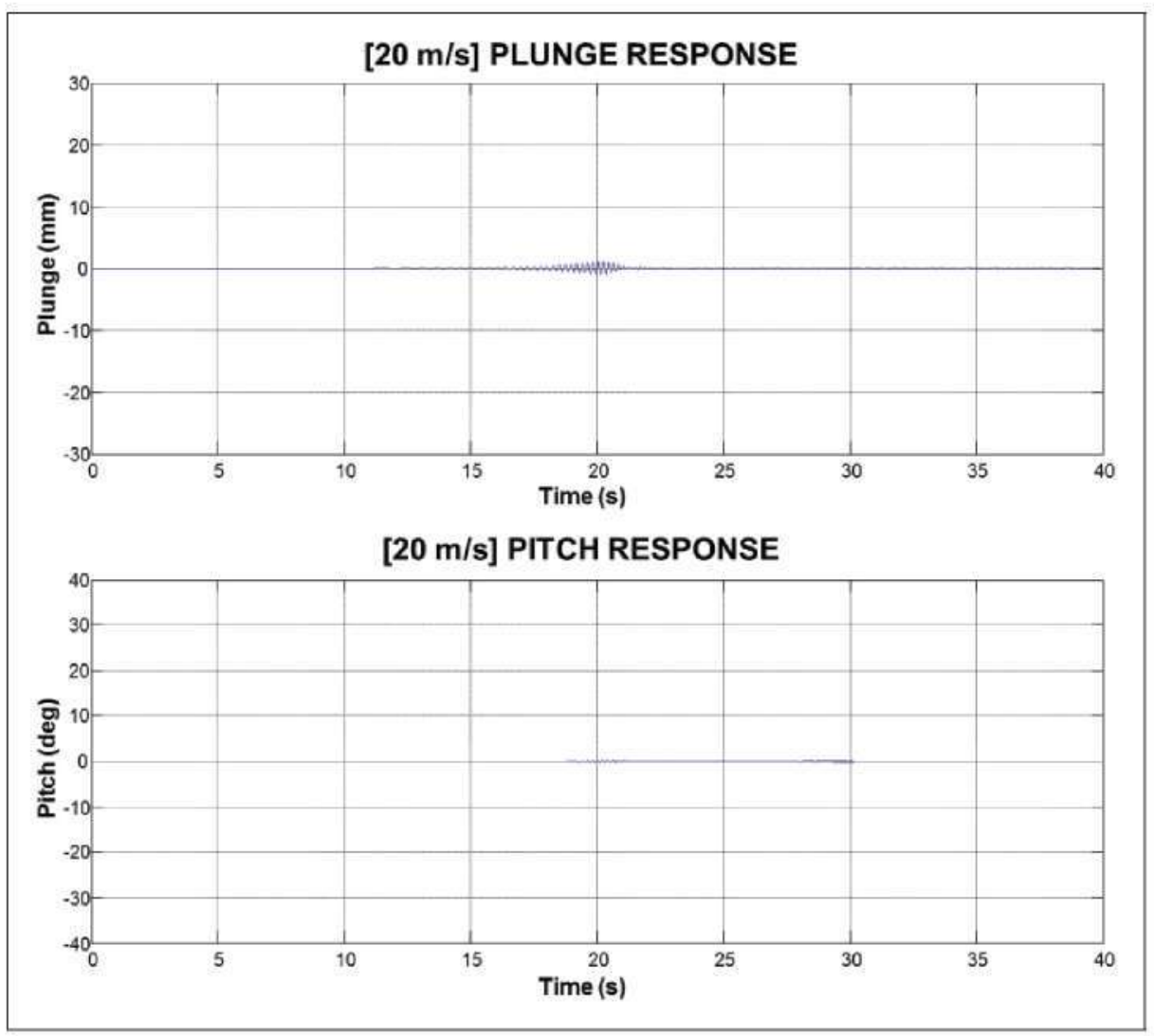

Figure 6. Plunge/Pitch time histories: No freeplay and an airspeed of $20 \mathrm{~m} / \mathrm{s}$.

after low speeds. In this case, the aerodynamic force governs the airfoil behavior in the plunge axis, different from without the freeplay (Figure 15). Two characteristic modes are distinguished in both the time and frequency planes: $4.2 \mathrm{~Hz}$ in the plunge and $9.6 \mathrm{~Hz}$ in the pitch (Figure 16).

\section{Free stream speed: $40 \mathrm{~m} / \mathrm{s}$}

At $40 \mathrm{~m} / \mathrm{s}$, the airfoil behavior in the plunge axis is noticeably different from that without freeplay
(Figure 17). However, elastic energy is produced for high frequency excitations. The coalescence mechanism is confirmed. The plunge characteristic frequency increases to $5.2 \mathrm{~Hz}$, and the pitch decreases to $9.4 \mathrm{~Hz}$ (Figure 18). The LCO Margin remains approximately unchanged.

\section{Free stream speed: $54 \mathrm{~m} / \mathrm{s}$}

At $54 \mathrm{~m} / \mathrm{s}$, the airfoil has developed a sustained LCO at $4.8 \mathrm{~Hz}$ (Figure 19). The "non-linear" mode 


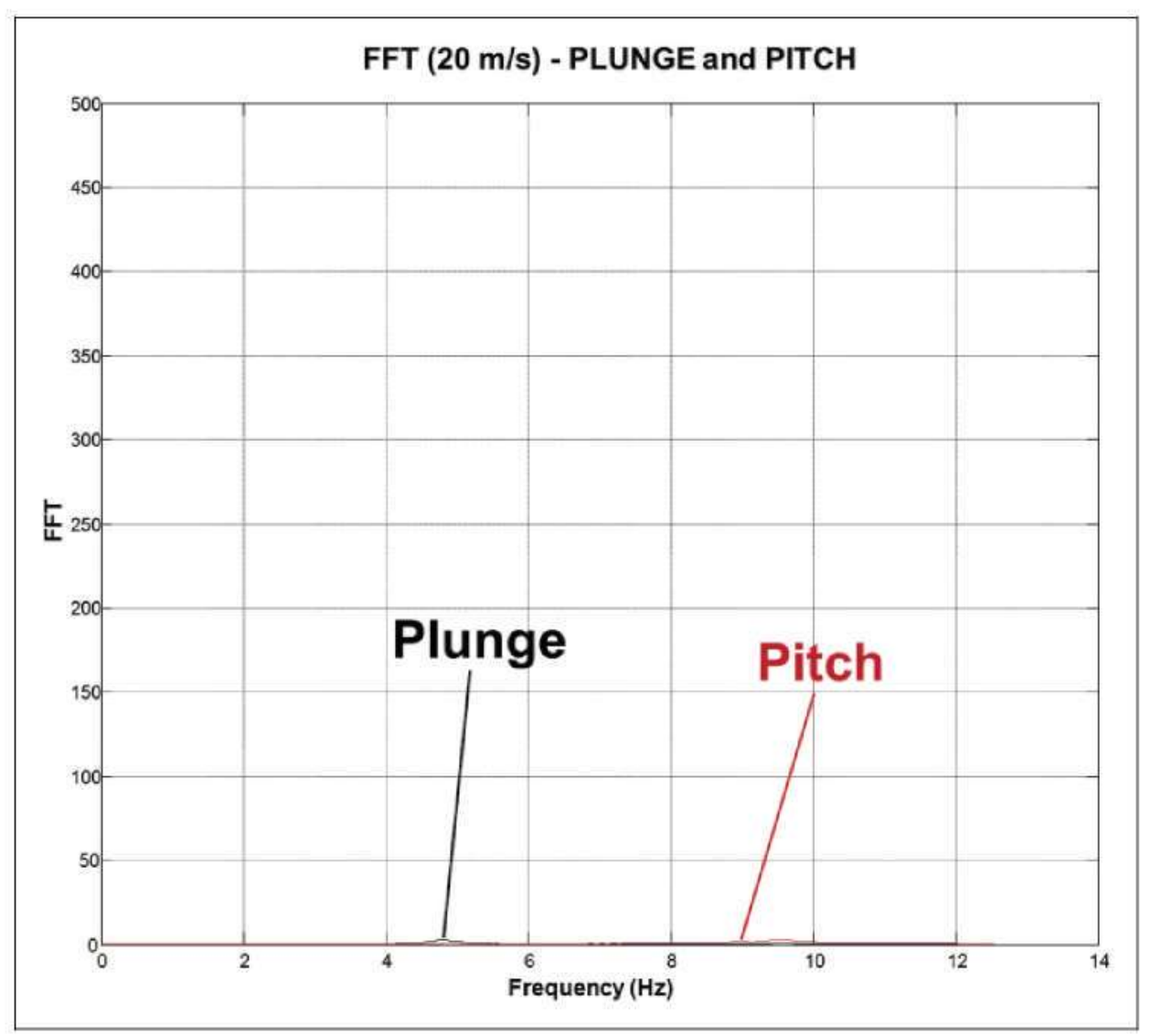

Figure 7. FFT: No freeplay and an airspeed of $20 \mathrm{~m} / \mathrm{s}$.

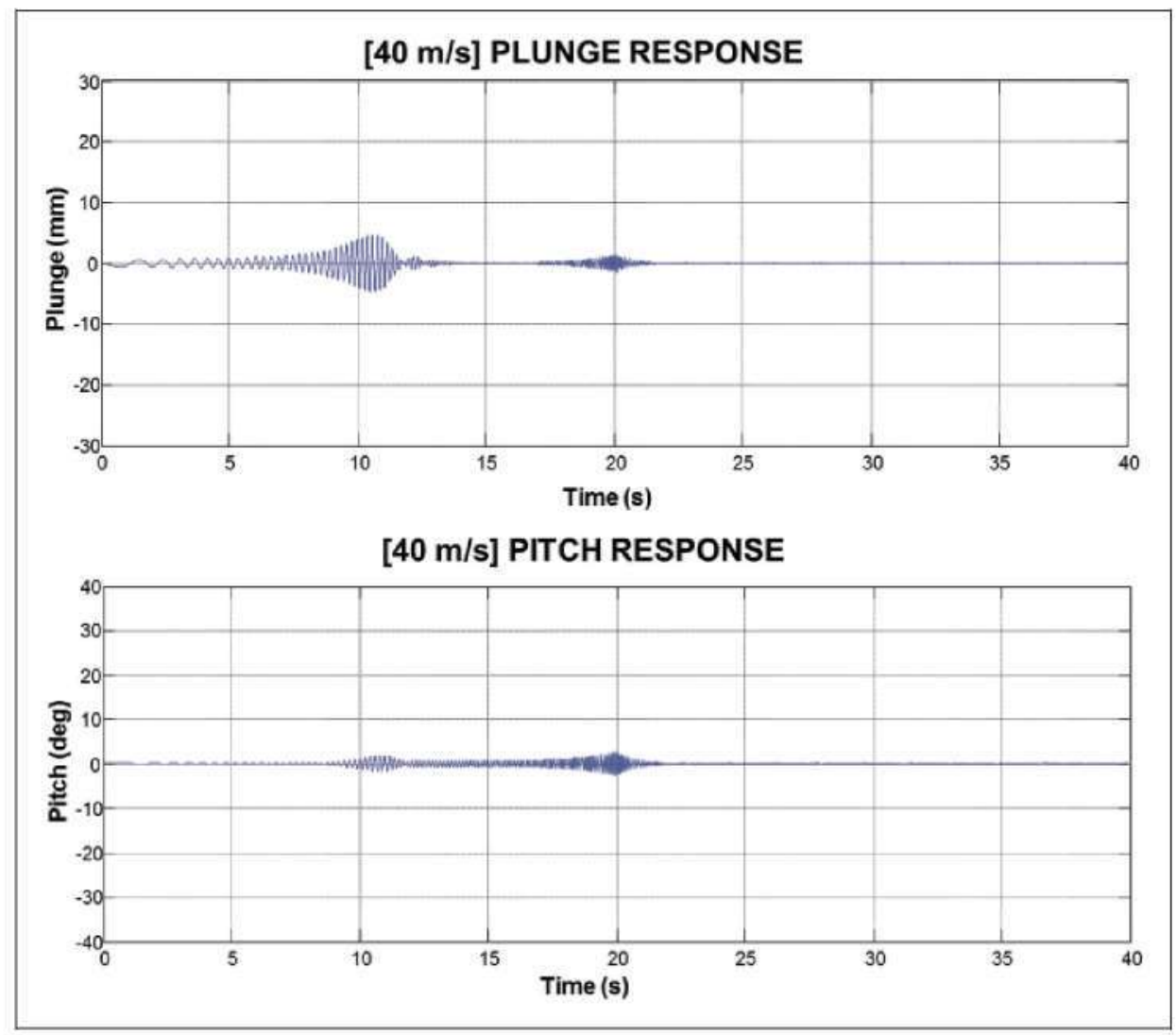

Figure 8. Plunge/pitch time histories: no freeplay and an airspeed of $40 \mathrm{~m} / \mathrm{s}$. 


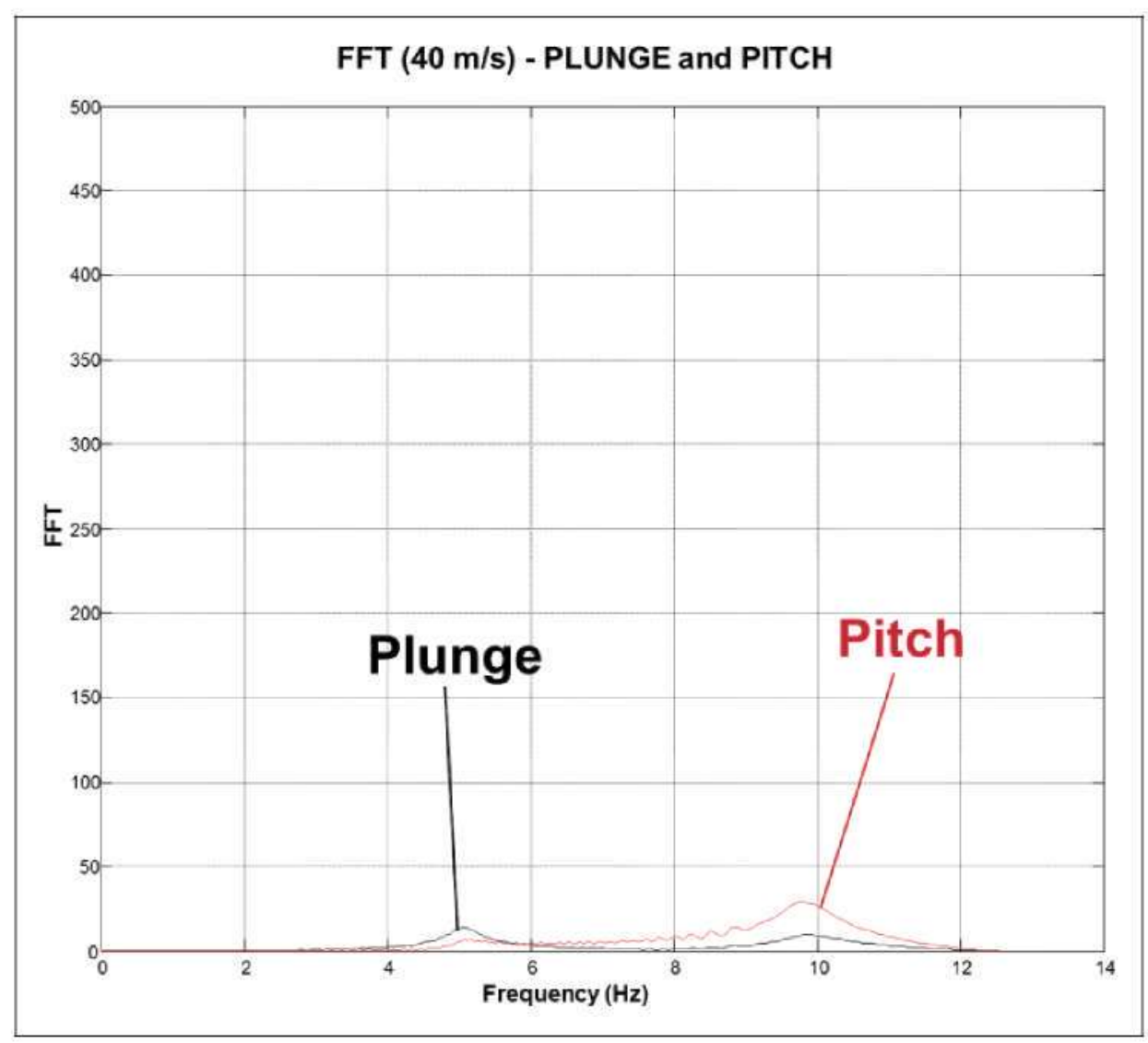

Figure 9. FFT: no freeplay and an airspeed of $40 \mathrm{~m} / \mathrm{s}$.

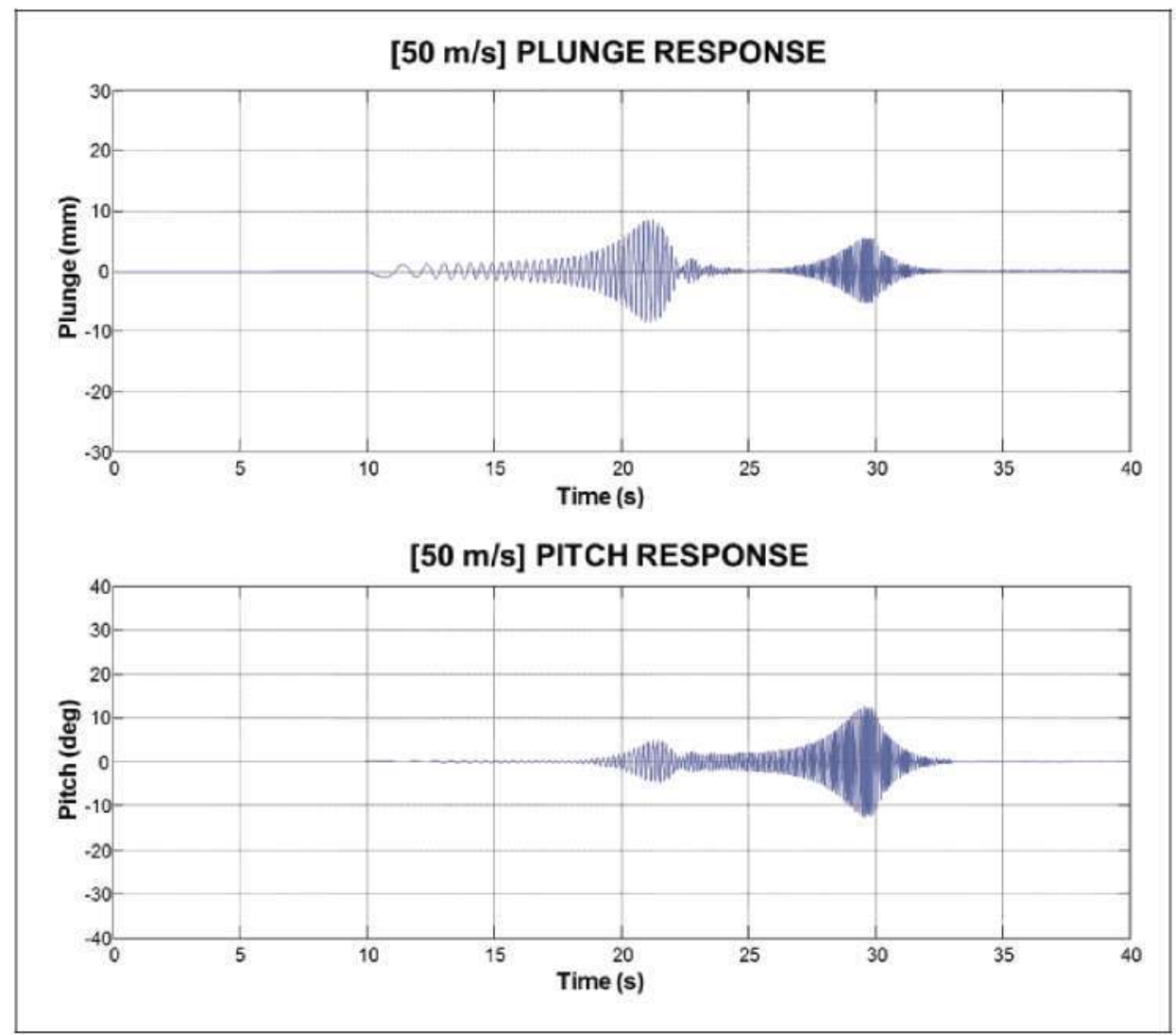

Figure 10. Plunge/pitch time histories: no freeplay and an airspeed of $50 \mathrm{~m} / \mathrm{s}$. 


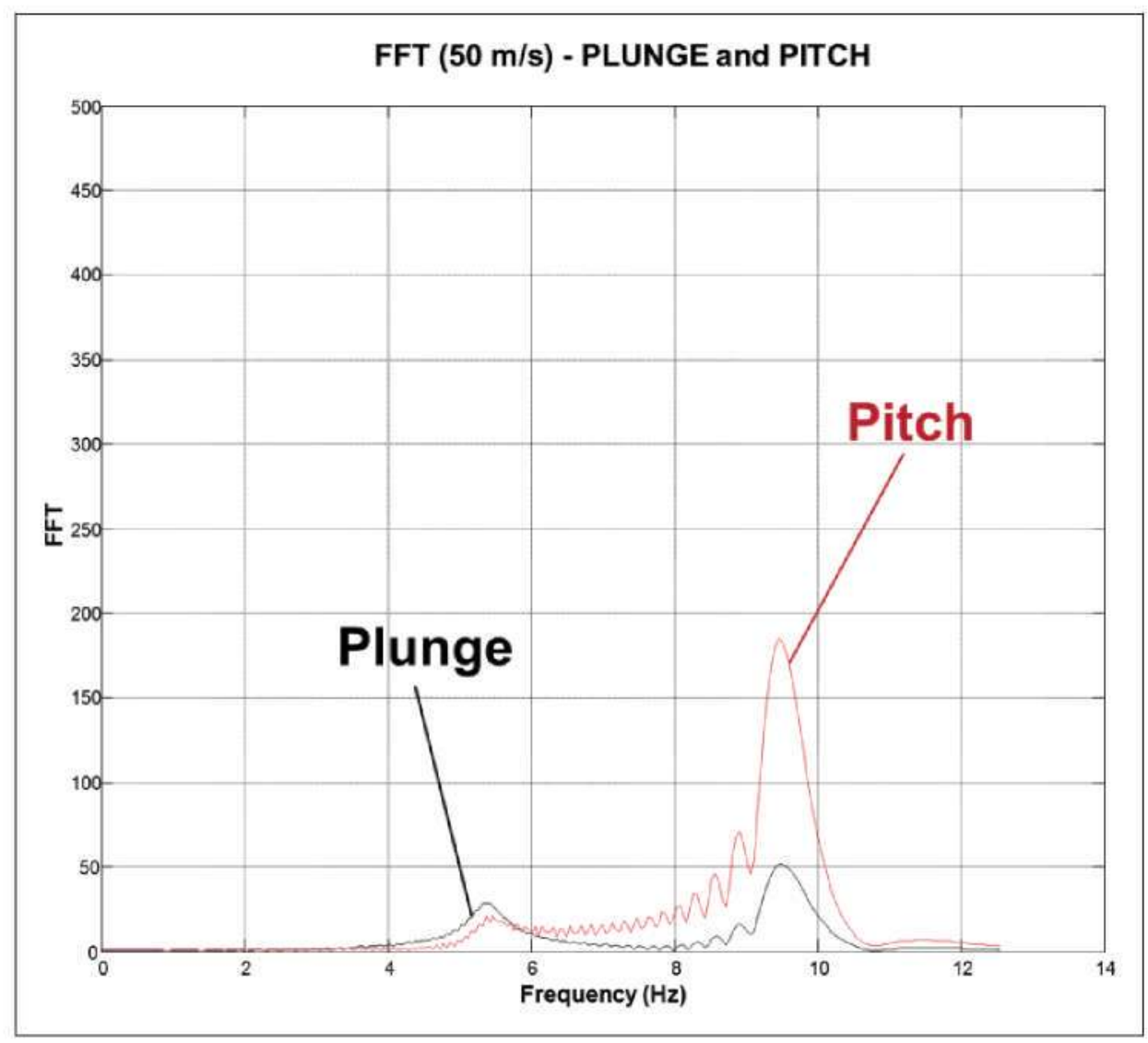

Figure II. FFT: no freeplay and an airspeed of $50 \mathrm{~m} / \mathrm{s}$.

associated with the freeplay has coupled with the elastic pitch response; this mechanism has allowed an LCO. At this stage, the FM value is 8800 , indicating that the airfoil remains below the flutter onset speed. Because the LCO Margin is at a maximum, this value indicates that the envelope expansion could continue beyond the LCO identified speed.

Considering the freeplay case, the classical modal coalescence still persists, but its identification is more unreliable than in the no-freeplay case. This unreliability results from the coalescence being performed with a "low energy" non-linear mode associated with the freeplay. The correspondent linear mode does not occur in the mechanism until the flutter conditions are fulfilled. An incipient (low amplitude) LCO can be envisaged at $47 \mathrm{~m} / \mathrm{s}$, having the LCO is fully developed at $54 \mathrm{~m} / \mathrm{s}$. With the LCO mechanism being linked to a plunge freeplay and quasi-steady aerodynamics, the LCO is maintained in an interval of airspeed ranging from $54 \mathrm{~m} / \mathrm{s}$ to $62 \mathrm{~m} / \mathrm{s}$ when the system characteristics are those defined for this simulation. Additionally, the LCO amplitude increases as airspeed increases to the flutter onset speed (Figure 20).

The LCO mechanism is also provided in the phase plane defined by the plunge and plunge rate in Figure 21.

Representing both the flutter and LCO margins, the results are obtained in Figure 22.

\section{Experimental validation: F I 8 test case}

The model was validated by using real F18 test data. ${ }^{5}$ The F18 maintains a wing folding system (see Figure 23), saving space when shipped in a carrier. Wing folding is a common source of freeplay because of the intensive use of the aircraft when operating from a carrier-type vessel. The certified flight envelope must consider this degradation process to avoid LCO phenomena, and the proposed methodology can help to validate these envelopes even after the early stages of a flight test campaign.

Flight flutter test campaigns must be performed every time a new external stores configuration needs to be validated for a fighter-type aircraft. Specifically for the F18, these campaigns aim not only to determine the flutter onset speed but also those areas of the flight envelope where LCOs can occur. For example, it is well known that the F/A-18 A/B aircraft can experience an unacceptable $5.0-6.0 \mathrm{~Hz}$ oscillation at low altitude and high speed when carrying heavy stores on the outboard wing pylons and AIM-9 missiles on the wing tips. ${ }^{21}$ In order to address this kind of phenomena while expanding the flight envelope in real-time, potential regions of non-linear behavior must be anticipated before proceeding with the next test point.

For flight flutter test purposes, the F18 is fitted with accelerometers and extensometers, whose signals 


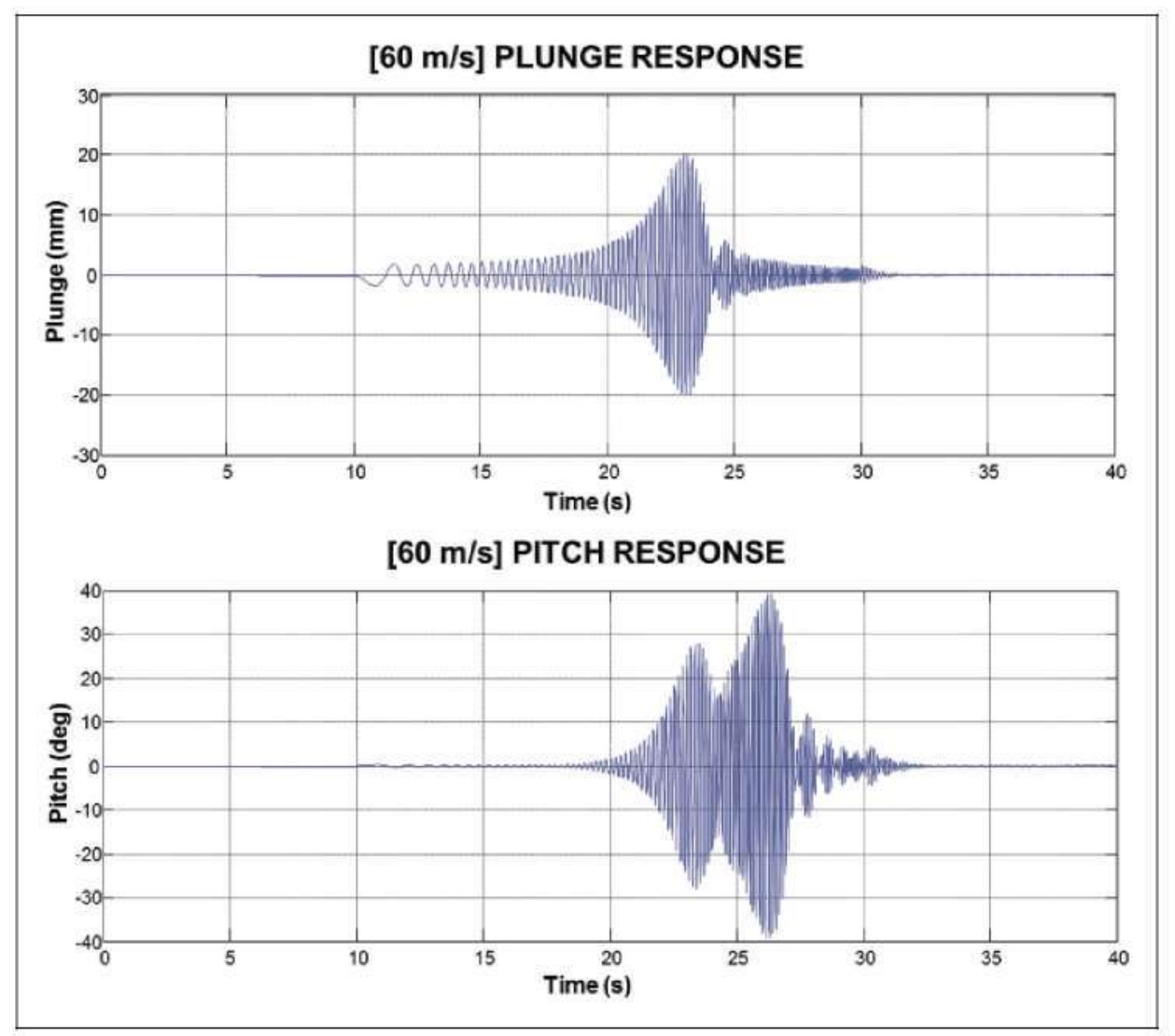

Figure 12. Plunge/pitch time histories: no freeplay and an airspeed of $60 \mathrm{~m} / \mathrm{s}$.

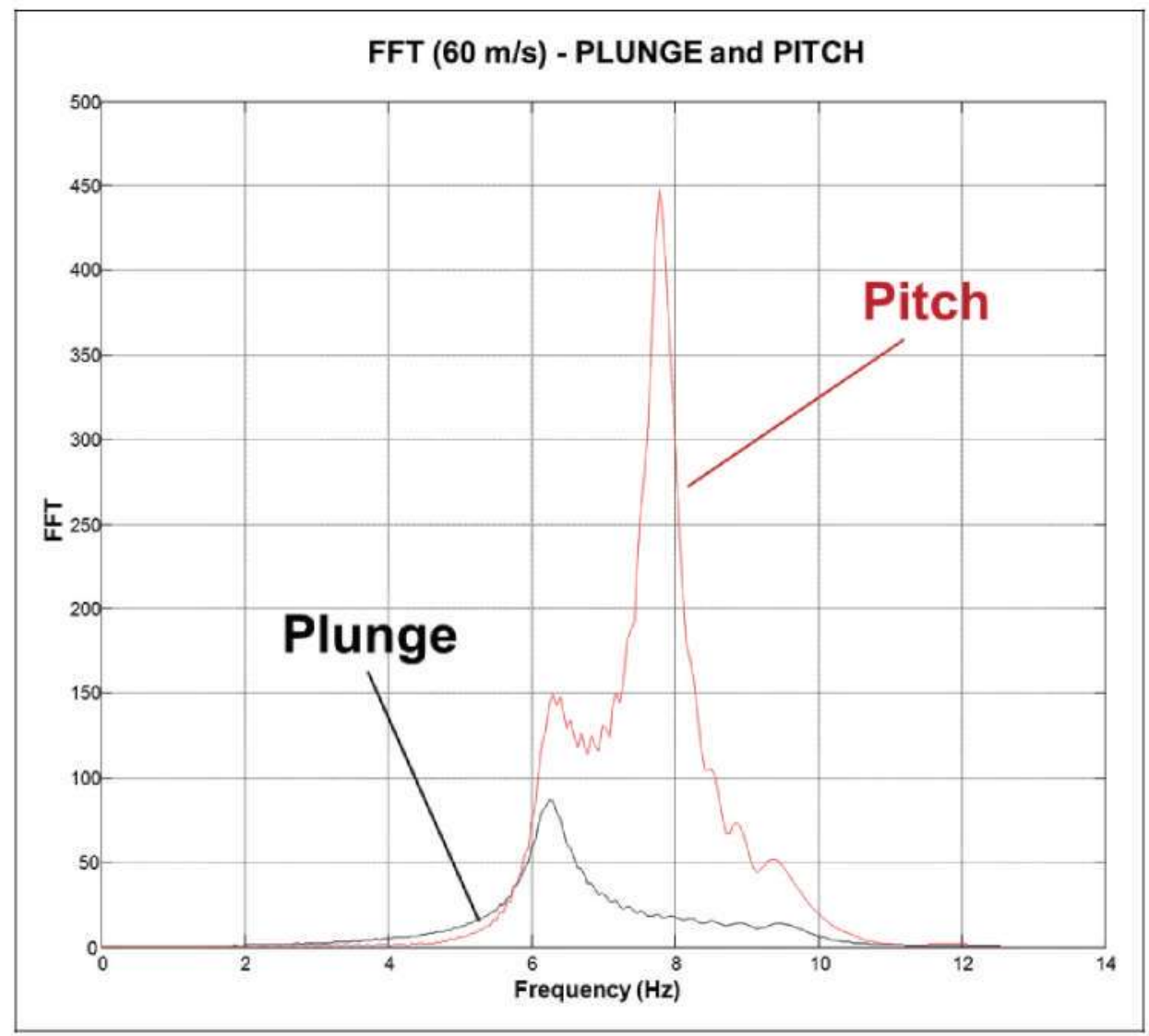

Figure 13. FFT: no freeplay and an airspeed of $60 \mathrm{~m} / \mathrm{s}$. 


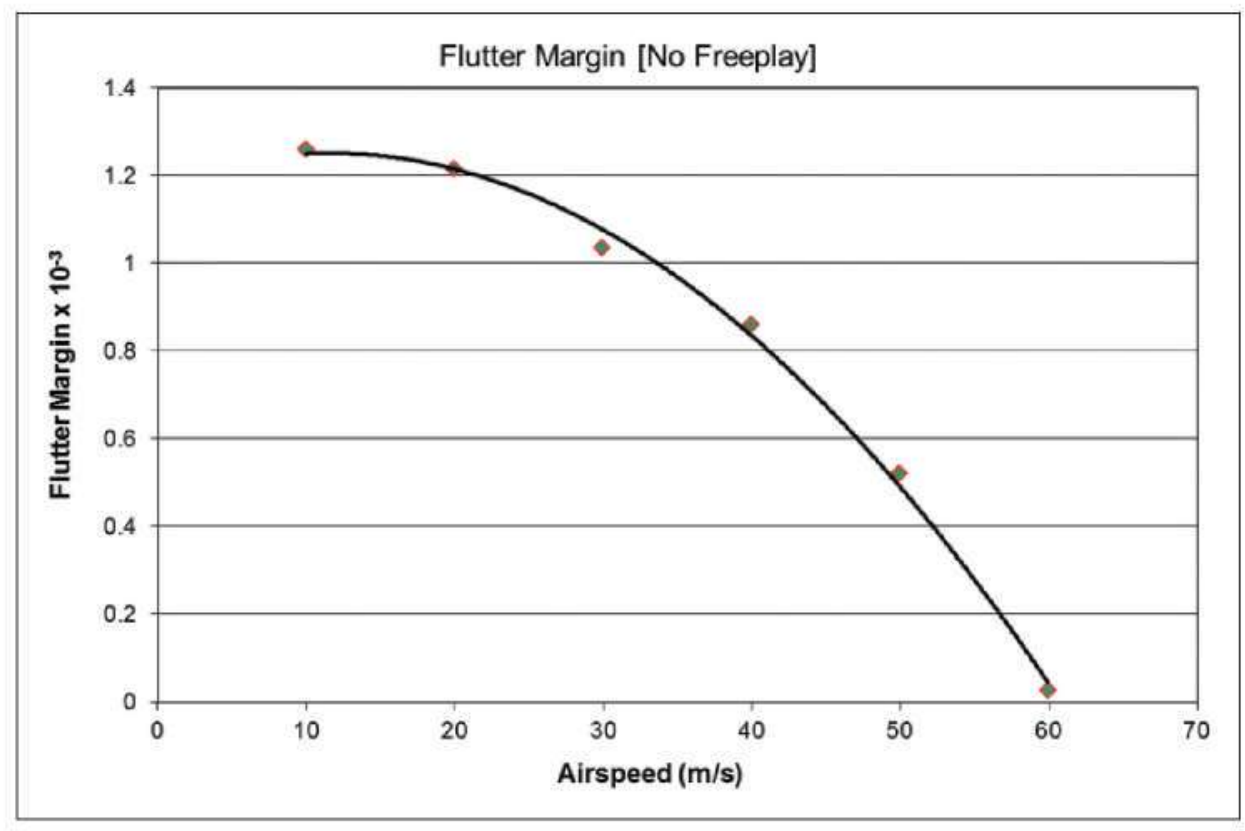

Figure 14. Flutter margin [no freeplay].

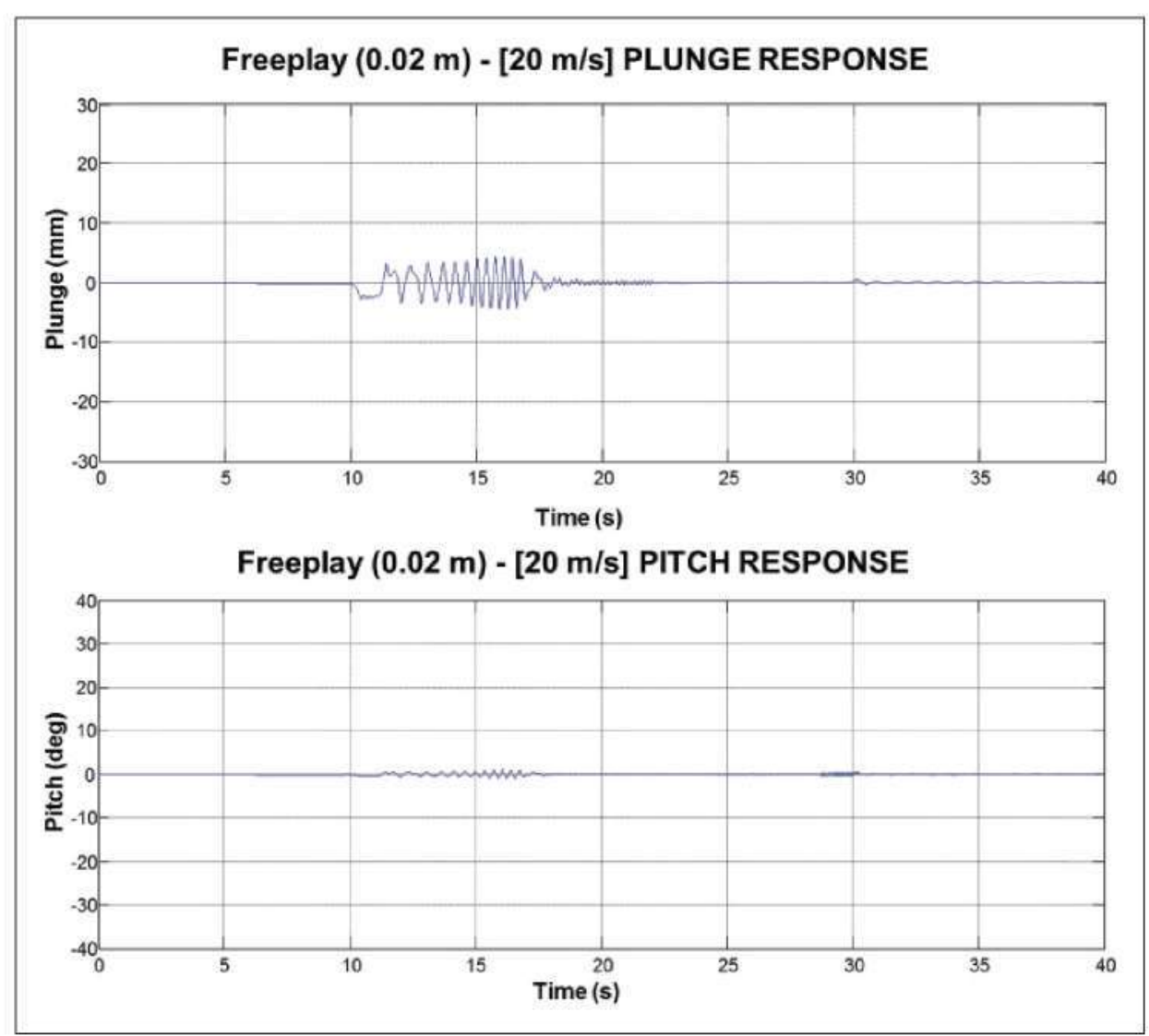

Figure 15. Plunge/pitch time histories: freeplay: $[-0.01+0.01] \mathrm{m}$ and an airspeed of $20 \mathrm{~m} / \mathrm{s}$.

are acquired and sent in real-time to a monitoring station. In addition, a Flutter Exciter Controller Unit (FECU), which allows the ailerons to be driven in sine dwells, sweeps or random, is also installed. FECU is used to command preprogrammed excitations into the aircraft in order to get the realtime structural response to those. Data from key accelerometers are analyzed and the frequency and damping for each identified mode are estimated. As a general rule for flutter test, if the estimated 


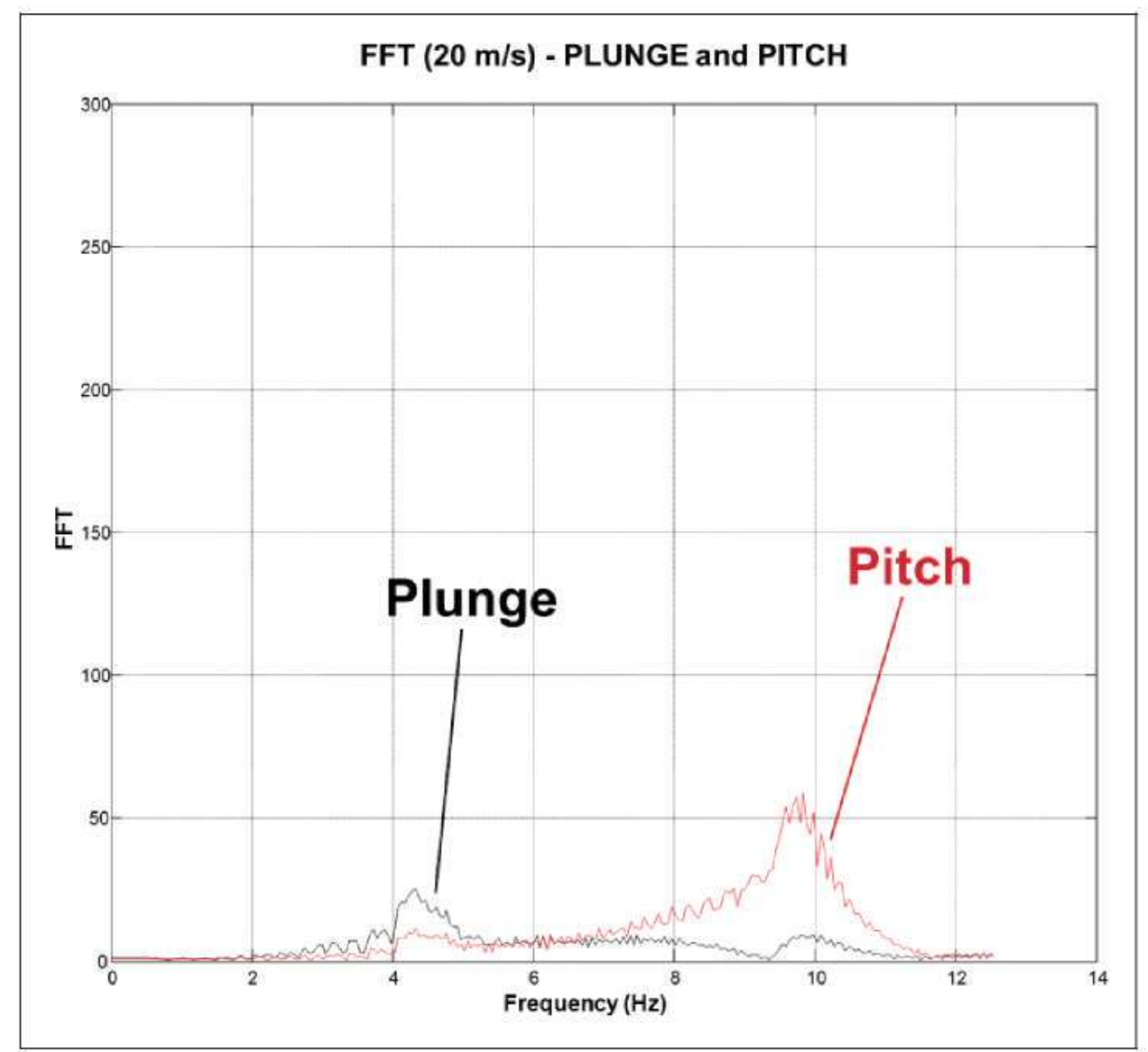

Figure 16. FFT: Freeplay: $[-0.01+0.01] \mathrm{ms}$ and an airspeed of $20 \mathrm{~m} / \mathrm{s}$.

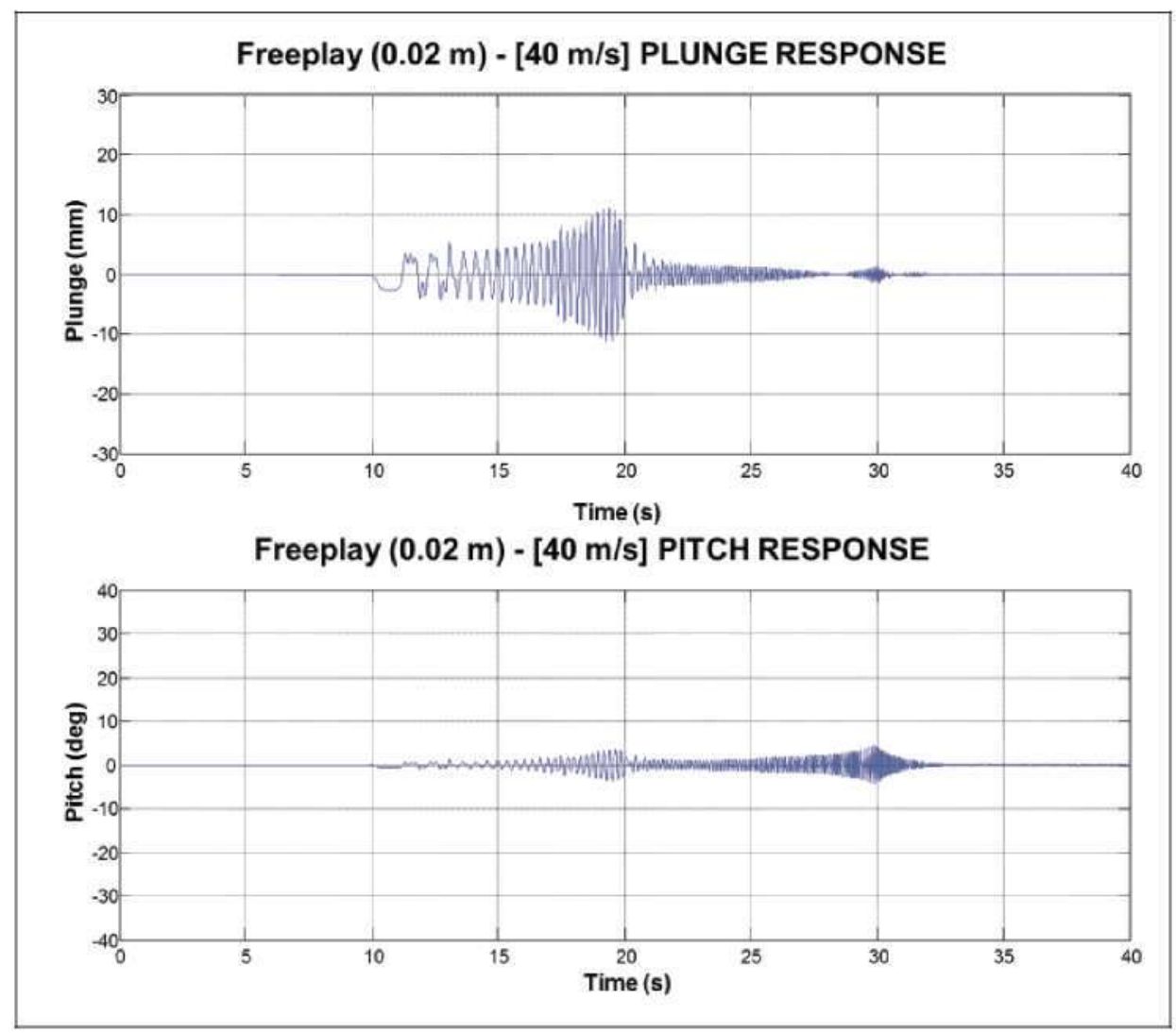

Figure 17. Plunge/pitch time histories: freeplay: $[-0.01,+0.01] \mathrm{m}$ and an airspeed of $40 \mathrm{~m} / \mathrm{s}$. 


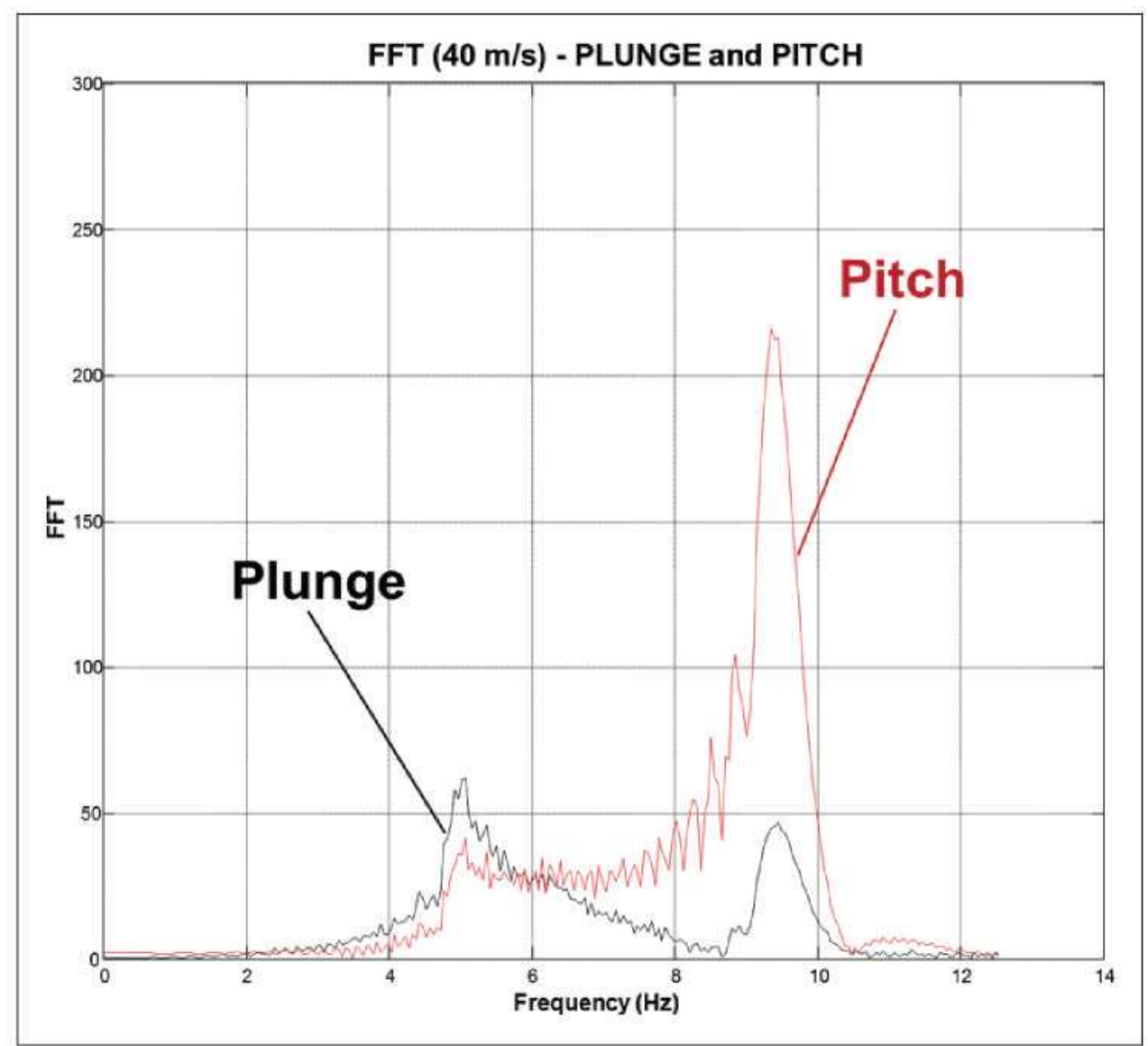

Figure 18. FFT: freeplay: $[-0.01,+0.01] \mathrm{m}$ and an airspeed of $40 \mathrm{~m} / \mathrm{s}$.

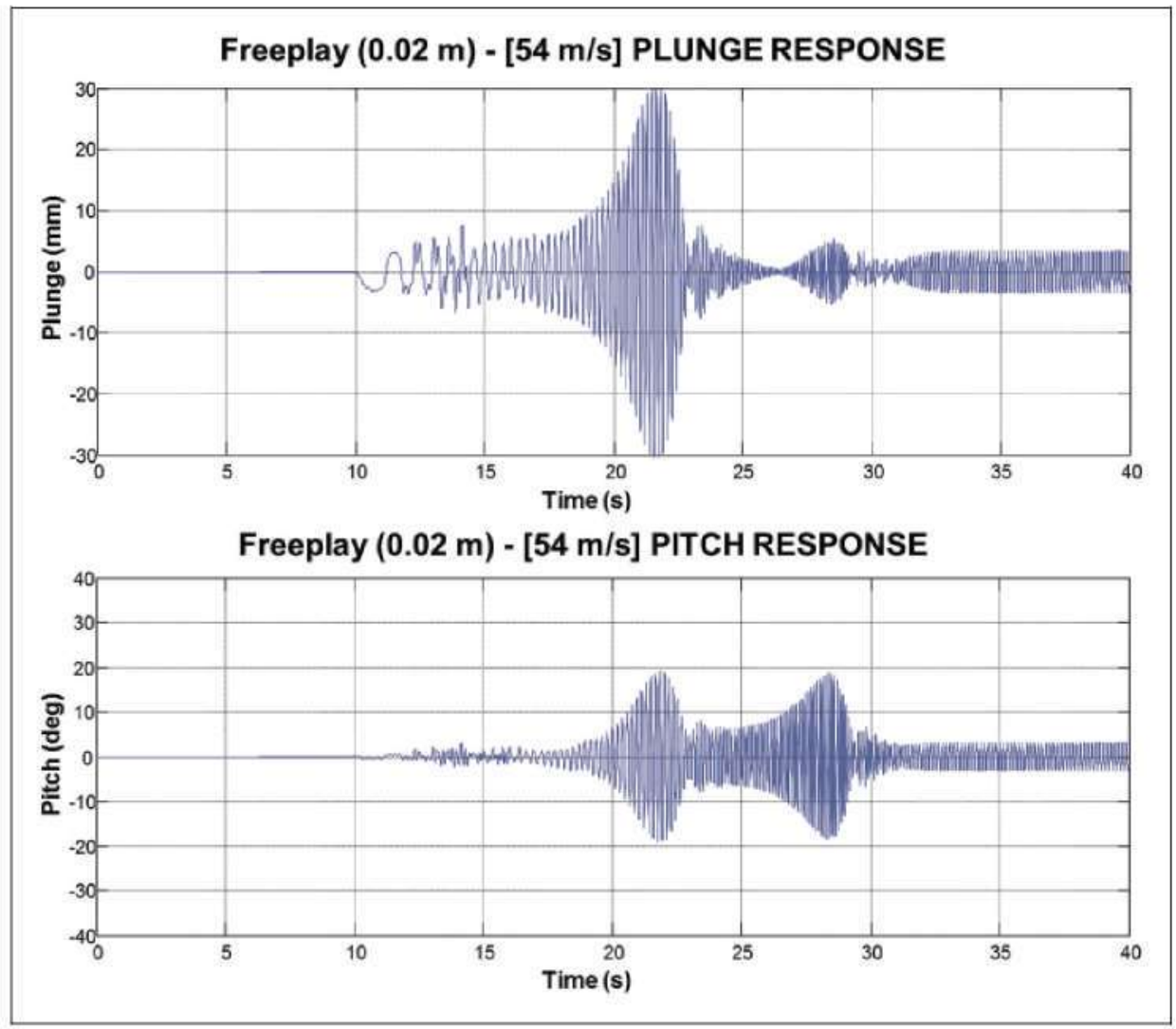

Figure 19. Plunge/Pitch time histories: Freeplay: $[-0.01,+0.01] \mathrm{m}$ and an airspeed of $54 \mathrm{~m} / \mathrm{s}$. 


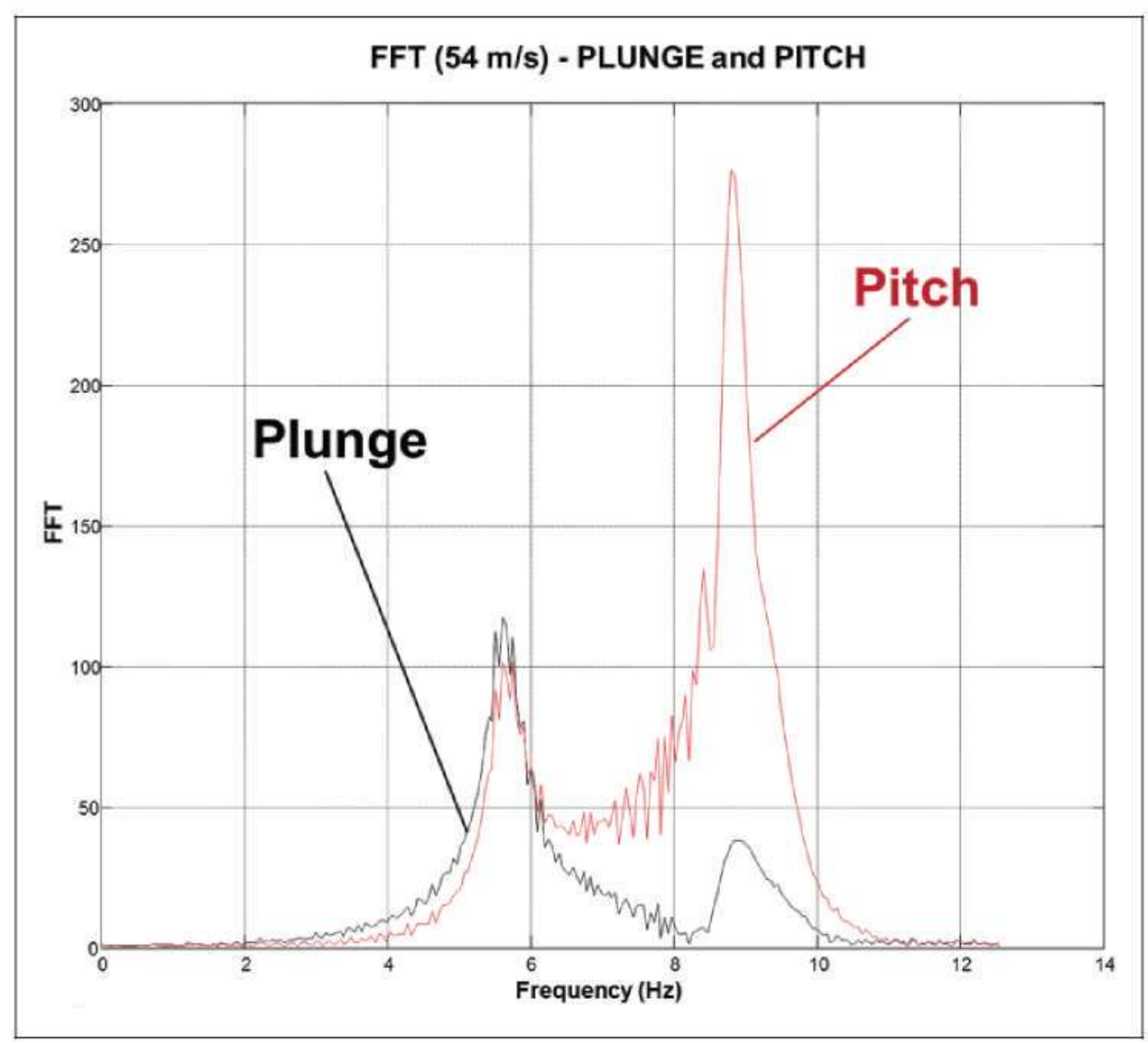

Figure 20. FFT: Freeplay: $[-0.01,+0.01] \mathrm{m}$ and an airspeed of $54 \mathrm{~m} / \mathrm{s}$.

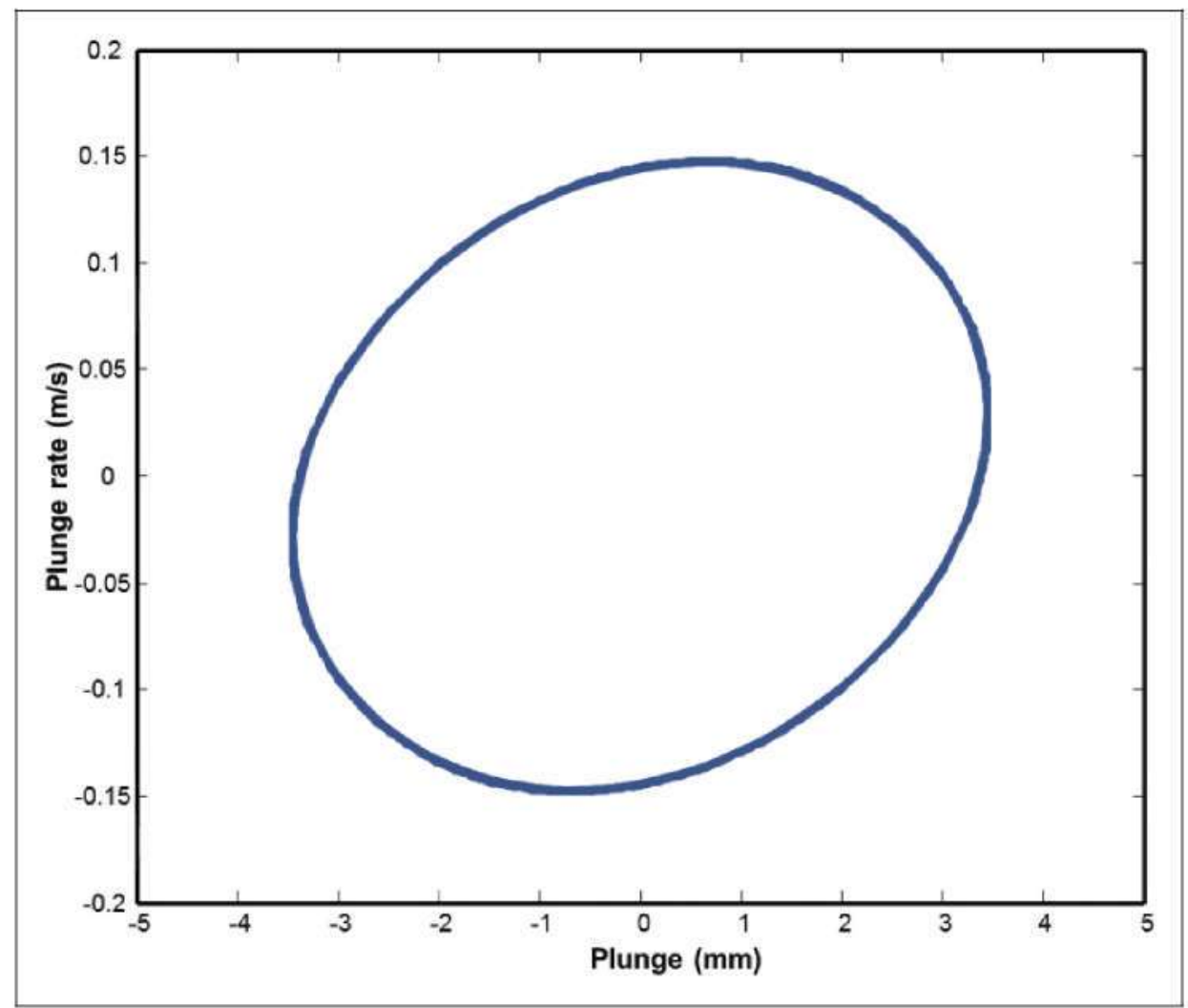

Figure 21. LCO depicted in the phase plane. 


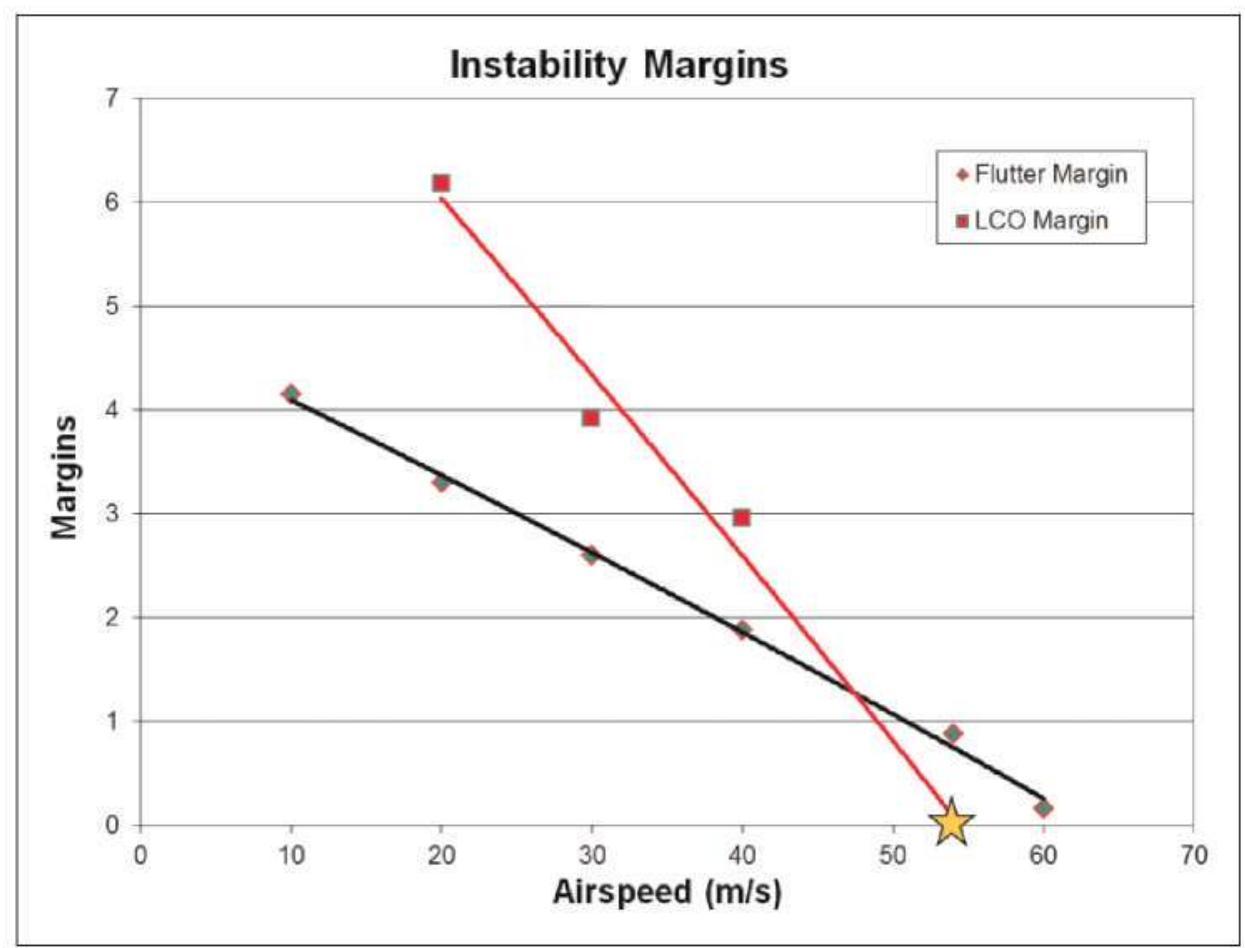

Figure 22. LCO margin: Freeplay $[-0.01,+0.01] \mathrm{m}$.

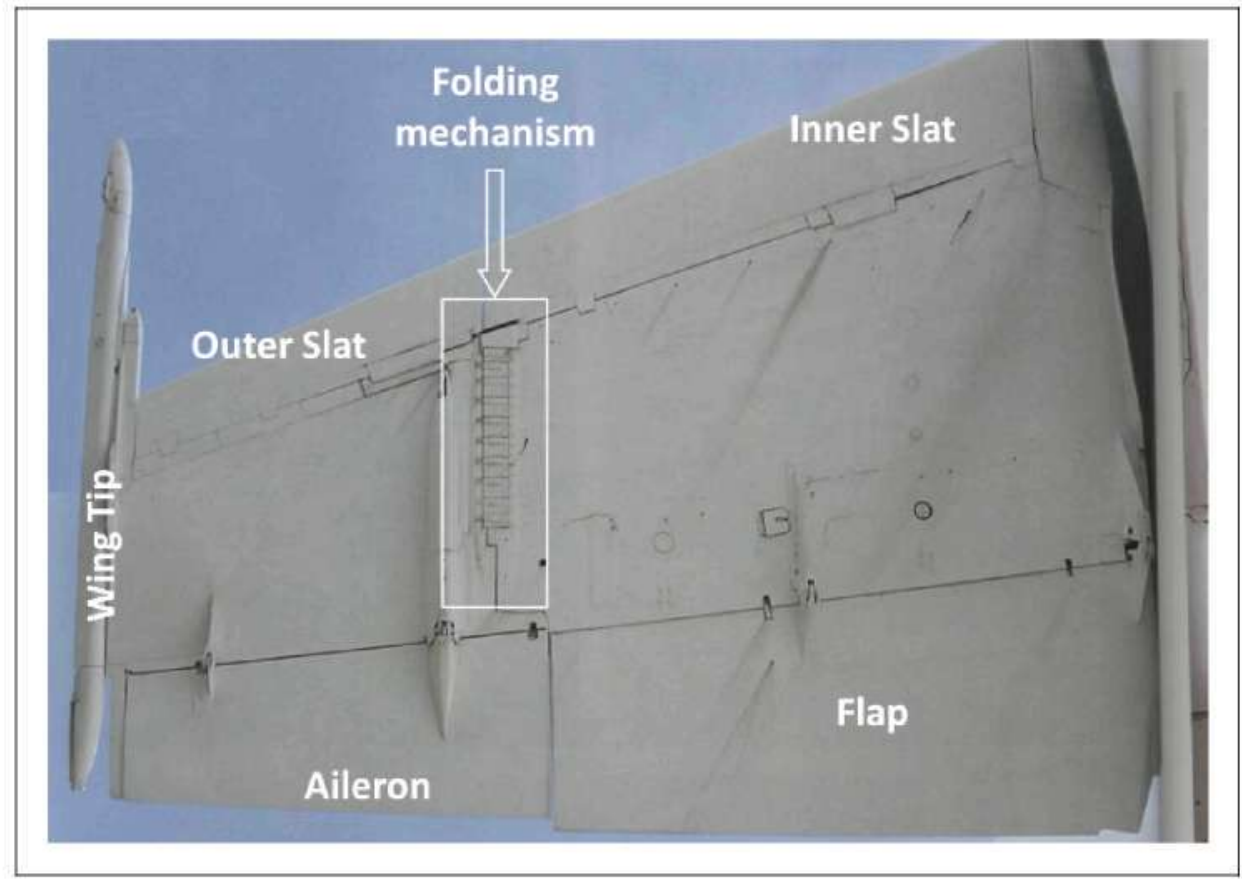

Figure 23. F/8 wing fold detail.

damping during a flight drops to less than $1.5 \%$ of critical or mode coalescence has been clearly identified, then any additional planned envelope expansion points at similar or greater Mach number of dynamic pressure should not be attempted. However, this procedure can be revisited if LCO is guessed to be present. In that case, LCO Margin, in addition to FM, can be used as an additional tool to progress in the envelope expansion using small speed increments. For that purpose, LCO Margin, as defined in the present paper, must be applied over on-conditioned flight test data using several numeric algorithms.

Data from Table 1 in the literature ${ }^{5}$ (when properly harmonized and using the minimum admissible damping value according to Military Specifications ${ }^{22}$ ) have been used to validate the model. The results show 


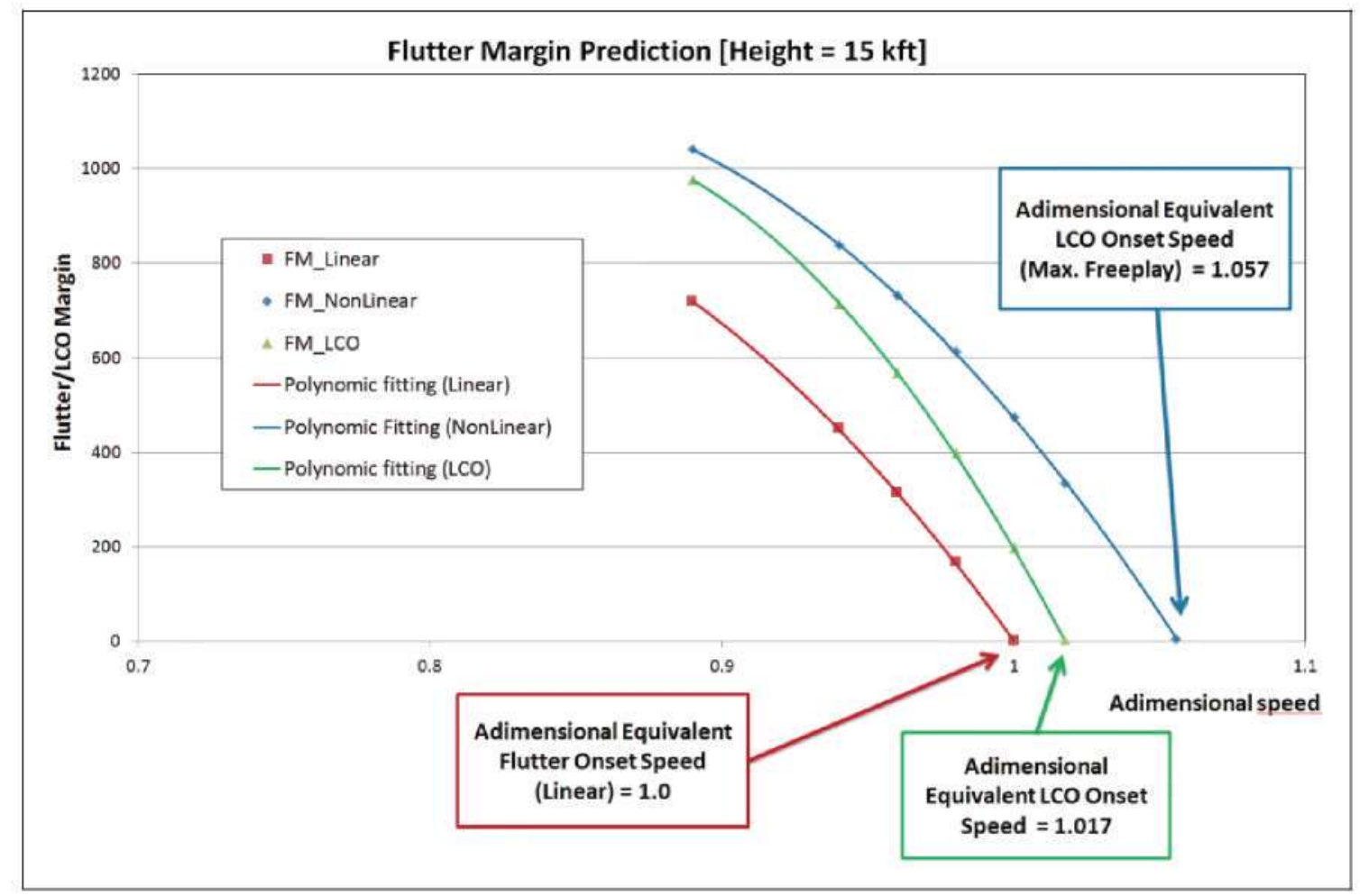

Figure 24. FI8 flight test: flutter margin vs LCO Margin.

(Figure 24) how the LCO margin is able to predict LCO conditions in a less conservative way than previously proposed margins. ${ }^{5}$

The following three margin functions have been used in Figure 24

$$
\begin{aligned}
& F M_{\text {Linear }}=\left(\frac{\omega_{2}^{2}-\omega_{1}^{2}}{2}\right)^{2} \\
& F M_{\text {Nonlinear }}=\left(\frac{\omega_{2}^{2}-\omega_{1}^{2} \cdot\left(\alpha_{d} / \pi-1\right)^{2}}{2}\right)^{2}
\end{aligned}
$$

$\alpha_{d}=$ Maximum allowed adimensional freeplay

$$
F M_{\mathrm{LCO}} \equiv e^{-\frac{2 \cdot 3 \pi}{\omega}}-1
$$

\section{Conclusions}

A LCO Margin function has been proposed for predicting LCOs associated to the plunge freeplay. As expected, when structural and inertial properties comply with certain combinations (stated in the formulation provided), LCOs can be encountered at speeds below flutter speeds. These lower speeds produce a flutter boundary identification that is excessively conservative. The LCO mechanism presented in this paper, which substantiates the review of the FM, has been verified through simulations based on "quasi-steady" aerodynamic models. ${ }^{23} \mathrm{In}$ addition, a flight test shows a good match with the results obtained.
The proposed LCO margin assists real-time decisions in continuing with envelope expansion when no damping is present, and this margin is shown as a complementary tool to the FM when freeplay is suspected to influence aeroelastic instability.

Finally, although the interactive Matlab-Simulink model helps to understand the LCO mechanism associated with freeplay, several improvements can be implemented to complete the investigation of this area. Unsteady aerodynamics and large deflections, along with the experimental data validation, are proposed by the authors as lines of future investigations.

\section{Declaration of Conflicting Interests}

The author(s) declared no potential conflicts of interest with respect to the research, authorship, and/or publication of this article.

\section{Funding}

The author(s) received no financial support for the research, authorship, and/or publication of this article.

\section{References}

1. Weissenburger JT and Zimmerman NH. Prediction of flutter onset speed based on flight testing at subcritical speeds. J Aircraft 1964; 1: 190-202.

2. Liu L, Wong YS and Lee BHK. Non-linear aeroelastic analysis using the point transformation method, part 1: freeplay model. $J$ Sound Vib 2002; 253: 447-469.

3. Conner MD, Virgin LN and Dowell EH. Accurate numerical integration of state-space models for 
aeroelastic systems with freeplay. AIAA $J$ 1996; 34 : 2202-2205.

4. Gordon JT, Meyer EE and Minogue RL. Nonlinear stability analysis of control surface flutter with freeplay effects. J Aircraft 2008; 45: 1904-1916.

5. Casado Corpas JL and López Diez J. Flutter margin with non-linearities: real-time prediction of flutter onset speed. Proc IMechE, Part G: J Aerospace Eng 2008; 222: 921-929.

6. Oliver $\mathbf{M}$, Climent $\mathbf{H}$, Rosich $\mathbf{F}$, Non-linear effects of applied loads and large deformations on aircraft normal modes. Proc. 36, Structural aspects of flexible aircraft control, chapter 21, specialists' meeting of the RTO applied vehicle techlology ponel (AVT). Ottawa, Canada, 18-20 October 1999.

7. Tian B and Ghia KN. Aeroelasticity analysis of aircraft wings in flutter-onset or post-flutter regime. In: Fifteenth international conference on numerical methods in fluid dynamics (ed P Kutler. J Flores and J-J Chattot), pp.304-349. Berlin, Heidelberg: Springer.

8. Price SJ, Alighanbari $\mathbf{H}$ and Lee BHK. The aeroelastic response of a two-dimensional airfoil with bilinear and cubic structural nonlinearities. J Fluids Struct 1995; 9: 175-193.

9. O'Neil T and Strganac TW. Aeroelastic response of a rigid wing supported by nonlinear springs. $J$ Aircraft $1998 ; 35: 616-622$.

10. AGARD. Numerical unsteady aerodynamic and aeroelastic simulation, 1997.

11. Schulze S. Simulation of nonlinear airfoil/controlsurface flutter at subsonic speeds using classical unsteady aerodynamics and an Euler method. In:International form on aeroelasticity and structural dynamics. CEAS/AIAA/ICASE/NASA Langley 1999. NASA/CP-1999-209136/PT 1:18.

12. Dowell EH, Thomas JP and Hall KC. Transonic limit cycle oscillation analysis using reduced order aerodynamic models. J Fluids Struct 2004; 19: 17-27.

13. Edwards JW, Spain CV, Keller DF, et al. Transport wing flutter model transonic limit cycle oscillation test. J Aircraft 2009; 46: 1104-1113.

14. Cooper JE. Towards faster and safer flight flutter testing. Defense Technical Information Center ADP014182, 2003.

15. Kehoe MW. A historical overview of flight flutter testing Center NDFR, National Aeronautics and Space Administration. Office of Management, Scientific and Technical Information Program. 1995.

16. Bisplinghoff RL. Ashley H. Halfman RL. Aeroelasticity, Dover publications. ISBN: 978-0-48669189-3, Mineola, NY, 1996.

17. Stoliker FN, AGARD-AG-300-VOL-14. AGARD Flight test techniques series. Volume 14: Introduction to flight test engineering, NATO science and technology, ISBN 92-836-1020-2, 1995.

18. Khalil HK. Nonlinear systems. Upper saddle river, NJ: Prentice Hall, 2002.

19. NASA-SP-415. Flutter testing techniques, NASA Langley research center, Hampton. VA. 1976.

20. Norton WJ. Limit cycle oscillation and flight flutter testing. In: Proceedings, society of flight test engineers, 21st annual symposium, pp. 3.4-1-3.4-12. August 1990.
21. Trame LW, Williams LE and Yurkovich RN. Active aeroelastic oscillation control on the F/A-18 aircraft. In: $A L A A$ guidance navigation and control conference, Snowmass, CO, 1985.

22. MIL-A-8870; 1987. Military specification: airplane strength and rigidity vibration, flutter and divergence. US Department of Defense, Military Standards, 20 May.

23. Fichera S, Quaranta $Q$ and Ricci S. Behaviour of an aeroelastic T-tail model with Rudder's freeplay: experimental and numerical investigation. $J$ Acrospace $S c i$ Technol Syst 2012; 91: 86-97.

\section{Notation}

non-dimensional distance from the mid chord to the elastic axis

$b$

$F_{\alpha}$

$F_{h}$

FFT

$F M$

h

h.

$\ddot{h}$

$\mathrm{Hz}$

$I_{\alpha}$

$K_{\alpha}$

$K_{h}$

$L$

$L C O$

$L C O$

$m$

M

$p$

$r_{\alpha}$

$S_{\alpha}$

$U$

$x_{\alpha}$

$\dot{\alpha}$

$\ddot{\alpha}$

$\alpha_{d}$

$\rho$

$\mu$

$\omega$

$\omega_{\alpha}$

$\omega_{h}$ airfoil mid chord

force in the pitch axis

force in the plunge axis

Fourier fast transform

flutter margin

plunge displacement

plunge rate

plunge acceleration

Hertz

mass moment of inertia about the elastic axis

spring constant in pitch

spring constant in plunge

lift

limit cycle oscillation

LCO margin

airfoil's mass

aerodynamic moment

differential operator

dimensionless radius of gyration

static mass moment per unit span

about elastic axis

free stream true velocity

distance between the elastic axis and the center of mass

pitch angle (under the assumptions

made, equals to angle of attack)

pitch rate

pitch angular acceleration

adimensional freeplay/initial

conditions parameter

freeplay in the plunge axis

density of air

$2 \pi \mathrm{pb} / \mathrm{m}$, mass parameter

LCO motion frequency

torsion structural natural frequency

bending structural natural frequency 